\title{
Optimization of Friction-Stir Welding of 6061-T6 Aluminum Alloy
}

\author{
I. V. Vysotskiy ${ }^{1}$, S. S. Malopheyev ${ }^{1}$, S. Yu. Mironov ${ }^{1 *}$, and R. O. Kaibyshev ${ }^{1}$ \\ ${ }^{l}$ Belgorod National Research University, Belgorod, 308015 Russia \\ *e-mail:mironov@bsu.edu.ru
}

Received November 12, 2019, revised November 12, 2019, accepted November 20, 2019

\begin{abstract}
In this work, two simple but effective strategies were proposed to optimize friction-stir welding of 6061-T6 aluminum alloy. The first one involved an optimization of welding variables to provide a combination of a relatively high welding temperature and the shortest possible thermal cycle during friction-stir welding. This inhibited precipitation coarsening in the heat-affected zone and resulted in considerable residual stress. Accordingly, the produced welds exhibited excellent strength characteristics under static and cyclic loading conditions. The second method was based on the application of the standard postweld T6 tempering. To avoid the abnormal grain growth, which usually occurs during solutionizing of aluminum frictionstir welds, a prestrain rolling was employed prior to the material tempering. This promoted an activation of recrystallization processes during subsequent heat treatment, thus suppressing the abnormal grain growth.
\end{abstract}

Keywords: heat-treatable aluminum alloys, friction-stir welding (FSW), heat treatment, precipitation strengthening, abnormal grain growth, fatigue

DOI: $10.1134 /$ S1029959920050057

\section{INTRODUCTION}

\subsection{Weldability of Heat-Treatable Aluminum Alloys}

Due to attractive combination of low density, good service properties and reasonably low cost, heat-treatable aluminum alloys are widely used in transportation industry. However, a significant problem of such materials is a relatively poor weldability by conventional fusion techniques. This necessitates using a riveting approach for manufacturing of large-scale aviation structures thus increasing their total weight and cost and degrading performance. In this regard, friction-stir welding (FSW), an innovative technology, is widely considered as a very promising candidate for joining of these alloys $[1,2]$. Being a solid-state technique, friction-stir welding avoids (or minimizes) solidification problems associated with the fusion welding and therefore may produce high-quality welds with excellent mechanical characteristics. In aviation industry, friction-stir welding may replace riveting and thereby principally improve the manufacturing technology.

Given industrial significance of friction-stir welding of heat-treatable aluminum alloys, significant efforts have been undertaken recently to explore the fundamental aspects of this process and thus to efficiently control the weld properties. Some of the most important results are briefly summarized below.

\subsection{Precipitation Phenomena Induced by Friction-Stir Welding}

Since the strength characteristics of the heat-treatable aluminum alloys are essentially contributed by nanoscale coherent precipitates, the particle behavior during friction-stir welding represents a particular interest.

Due to the large temperature gradient associated with friction-stir welding, the welded material may experience complex precipitation phenomena. In the microstructural region exposing at relatively low temperatures (the so-called heat-affected zone), an essential coarsening of the strengthening dispersoids is usually found [3-26]. This normally leads to the loss of coherent relationship between the particles and aluminum matrix [13, 21, 27]. The both processes result in essential material softening $[6-8,14,15,19,21,25$, $28,29]$. In $7 x x x$ alloys, a development of precipitation-free zones along grain boundaries has been also observed $[3,30]$. 
In the microstructural areas experiencing an influence of relatively high temperatures (i.e., the so-called thermo-mechanically affected zone and the stir zone), the precipitates typically dissolve, thus also degrading the strength characteristics of the welded material [38, 11, 13-15, 17-22, 24-26, 31-39]. However, depending on the cooling rate, the particles may partially reprecipitate during weld cooling cycle $[3,14,15,19$ $23,31,39]$, thus partially restoring the material strength. Since the welded microstructure may contain numerous crystal defects (e.g., dislocations, subgrain and grain boundaries) as well as survived secondphase particles, the reprecipitation may occur in a heterogeneous manner [3, 22, 23, 31].

The particles coarsening observed in the heat-affected zone is often considered as the most detrimental effect of friction-stir welding, because it could not been recovered during standard postweld aging treatment $[5,28]$. This phenomenon may give rise to relatively low joint efficiency ${ }^{1}$ of friction-stir welded heat-treatable aluminum alloys.

It was suggested by the authors that the production of high-strength welds in heat-treatable alloys may be possible via enhancement of the particle dissolution but suppressing of the particle coarsening processes. In this case, friction-stir welding thermal cycle would be similar to a typical solution heat treatment and thus the weld properties could be efficiently recovered duing the subsequent aging.

The particle dissolution may be achieved by the increasing of the weld temperature at high tool rotational rates. On the other hand, the suppression of the particle coarsening may be realized by the shortening of the weld thermal cycle at relatively high welding speeds. It was hypothesized, therefore, that an optimized friction-stir welding, which involves a combination of a high tool rotational rate and a high welding speed, may improve the joint efficiency of the friction-stir welded heat-treatable aluminum alloys.

\subsection{Abnormal Grain Growth during Post-Weld Heat Treatment}

An alternative approach to avoid the undesirable effect of the particle coarsening in the heat-affected zone is an application of the standard T6 tempering of the produced welds. T6 tempering includes solutionizing treatment followed by artificial aging and may provide a relatively uniform precipitation of strengthening dispersoids across the welded material. How-

\footnotetext{
1 The joint efficiency represents the ratio of the strength of the welded joint to the strength of the base material.
}

ever, the first experiments in this area have shown that the high-temperature annealing of friction-stir welded materials frequently gives rise to an abnormal grain growth in the stir zone [28, 40-76]. This phenomenon involves a catastrophic growth of few grains, which may consume an entire stir zone and thus result in substantial degradation of weld ductility [28].

Despite the abnormal grain growth is known for many years, the origin of this phenomenon is still not completely clear. The extensive recent research has demonstrated that the abnormal grain growth in friction-stir welded joints is sensitive to welding conditions; specifically, the welds produced at relatively high heat-input usually demonstrate relatively high thermal stability [40-48]. It has been also established that the catastrophic grain growth often initiates either from the upper surface of the stir zone or from the weld root $[40,45,48-51]$. This observation is sometimes attributed to a specific microstructures produced in these areas during friction-stir welding [49]. It is interesting to note that crystallographic orientations of the abnormally growing grains have been recently found to be not random [50]. By analogy with the theory of recrystallization texture, this effect was explained in terms of increased mobility of $40^{\circ}\langle 111\rangle$ boundaries in face-centered cubic crystals [77].

From a broad perspective, the abnormal grain growth in the friction-stirred materials is often interpreted in terms of the so-called Humphreys' cellular model $[78,79]$, i.e. virtually attributed to a local imbalance between the grain-growth pressure and the pinning force exerting by either low-angle boundaries or second-phase particles. It should be emphasized in this context, that the friction-stir welded materials are characterized by a considerable microstructural gradient, which is not accounted in the above model. Accordingly, the genesis of the abnormal grain growth in friction-stir welds is still not completely clear and therefore there is no clear understanding of how to suppress this effect.

It is worth noting in this regard that $\sim 50$ years ago a simple but effective approach for inhibition of the abnormal grain growth has been proposed [80]. It involved a prestrain rolling and was based on the idea of activation of recrystallization instead of the abnormal grain growth during subsequent annealing. To the best of the authors' knowledge, this technique has not been applied for friction-stir welded material so far.

\subsection{Fatigue Performance of Friction-Stir Welds}

Since the welded structures in transportation sector are typically undergone a cyclic loading, an evaluation 
of the fatigue behavior of friction-stir welded heattreatable aluminum alloys is of particular importance. Accordingly, this topic is currently attracting a substantial interest, thus being a research hotspot $[1,2,4$, 81-107].

An extensive research over the last two decades has conclusively demonstrated that fatigue properties of friction-stir joints are superior to that of conventional fusion welds $[1,2,81-83]$. On the other hand, fatigue performance of friction-stir weldments is normally lower than that of the base material $[1,2,84$, $85]$.

It is long time known that a fatigue crack often (though not always) initiates from the imperfections of a specimen surface. Accordingly, the characteristic tool marks, which are normally produced on a weld surface during friction-stir welding, are of a great concern. The relatively sharp profile of these weld features give rise to stress concentrations and therefore those may serve as favorable sites for the fatigue crack nucleation $[1,2]$. Therefore, an elimination of such tool marks by a machining prior to the fatigue tests may essentially enhance the fatigue life $[1,2$, 86].

In the machined welds, where the surface finish is not a critical issue, three factors are believed to play the key role in fatigue resistance: welding defects, residual stress, and microstructure $[1,2]$. Without detailed consideration of these factors, as well as their interactions, it is hard to explain the fatigue behavior. This may be one of the possible reasons for relatively large experimental scattering of the fatigue results reported in the friction-stir welding literature [2].

Despite the welding defects are usually considered to be deteriorating for the fatigue behavior, it has been recently shown that up to a certain size they may be tolerable without significant compromising of fatigue life [87]. On the other hand, due to the specific character of friction-stir welding process, the produced welds normally contain an unbonded region at the weld root (the so-called "kissing bond") [108]. This inherent attribute of friction-stir welding joint my serve as a precursor for a fatigue crack $[88,89]$. Accordingly, this issue should be taken into account when considering even nominally defect-free welds.

Since friction-stir welding results in localized heating, the concomitant thermal expansion of the welded material gives rise to residual stress. This may significantly affect fatigue behavior [1, 2, 90-96]. Specifically, the nucleation as well as propagation of the fatigue cracks is well known to be promoted the tensile residual stress. On the other hand, the compressive re- sidual stress is believed to be beneficial for suppression of the fatigue cracks. Often, an introduction of the compressive stress in friction-stir welded materials, for instance, by using a shot peening or a lowplasticity burnishing, are recommended to improve the fatigue resistance $[92,93,95]$. On the other hand, a stress-relief heat treatment may result in degradation of the fatigue strength [2].

Considering the microstructural factor influencing the fatigue behavior, the precipitation coarsening in the heat-affected zone is believed to be the most undesirable effect [11, 109-112]. Specifically, the fatigue failure is frequently observed to occur in the heat-affected zone [111, 112].

It has been suggested that the optimization of friction-stir welding conditions, as discussed in Sect. 1.2, may essentially narrow the heat-affected zone as well as to result in relatively high compressive residual stresses. Both these factors may improve fatigue performance of friction-stir welded heat-treatable alloys.

\subsection{Motivation of This Work}

Significant microstructural changes occurring during friction-stir welding as well as during subsequent heat treatment may result in degradation of mechanical properties of heat-treatable aluminum alloys. Therefore the aim of the present work was an optimization of these technological steps in order to provide a nearly-100-pct joint efficiency. Two strategies were used for this purpose.

First, the welding variables were optimized to ensure a combination of a relatively high welding temperature and the shortest possible thermal cycle during friction-stir welding. This approach should result in relatively homogeneous distribution of strengthening precipitates during the standard postweld aging treatment.

Second, a prestrain rolling of friction-stir welded material was applied in order to suppress the abnormal grain growth during the standard postweld $\mathrm{T} 6$ tempering.

\section{EXPERIMENTAL}

\subsection{Program Material}

The material used in the present investigation was a commercial AA6061 aluminum alloy with measured chemical composition (wt \%) of $0.88 \mathrm{Mg}, 0.66 \mathrm{Si}$, $0.72 \mathrm{Fe}, 0.26 \mathrm{Cu}, 0.12 \mathrm{Mn}, 0.12 \mathrm{Cr}, 0.09 \mathrm{Zn}$, and balance Al. This is a typical heat-treatable aluminum alloy, which may serve as a representative example for in- 
vestigation of friction-stir welding behavior of such materials. The material was produced by semicontinuous casting followed by homogenization at $380^{\circ} \mathrm{C}$ $(653 \mathrm{~K})$ for 1 hour and subsequent extrusion at this temperature to $75 \%$ of area reduction. To produce the peak aged condition, the extruded material was subjected to the standard T6 tempering, i.e., it was solutionzed at $550^{\circ} \mathrm{C}(823 \mathrm{~K})$ for 1 hour, water quenched, and then artificially aged at $160^{\circ} \mathrm{C}(433 \mathrm{~K})$ for 8 hours.

\subsection{Friction-Stir Welding Procedure}

The T6-tempered material was friction-stir butt welded using an AccurStir 1004 friction-stir welding machine. The thickness of the welded sheets was $3 \mathrm{~mm}$. The welding tool was fabricated from a tool steel and consisted of a shoulder of $12.5 \mathrm{~mm}$ in diameter and an M5 cylindrical probe of $1.9 \mathrm{~mm}$ in length. To avoid a formation of the "kissing bond" defect (and thus ensuring a full-thickness joining), a double-side friction-stir welding was applied in the same welding direction. To provide a relatively high welding temperature, the maximal tool rotational speed (allowable by the used friction-stir welding machine) of $1100 \mathrm{rpm}$ was used. To examine the effect of the welding speed, three welding trials were conducted at the tool travel speeds of 125, 380 and $760 \mathrm{~mm} / \mathrm{min}^{2}$. In all cases, the tool tilting angle of $2.5^{\circ}$ was employed. The principal directions of the friction-stir welding geometry were denoted throughout as the welding direction (WD), transverse direction (TD) and normal direction (ND).

\subsection{Postweld Heat Treatment}

To recover mechanical properties of the welded material, the postweld heat treatments were applied. Those included either the artificial aging at $160^{\circ} \mathrm{C}$ ( $433 \mathrm{~K}$ ) for 8 hours or the T6 tempering in the manner described in Sect. 2.1. To minimize the possibility of natural aging of the welded material and hence its potential influence on mechanical properties, all annealing procedures were performed within $\sim 20 \mathrm{~min}$ after the friction-stir welding process.

To suppress the possible abnormal grain growth, which may occur during the T6 tempering, a prestrain rolling was applied. To this end, selected welds were cold rolled in the $\mathrm{WD} \times \mathrm{TD}$ plane to either 10 or $20 \%$ of thickness reduction prior to the heat treatment.

\footnotetext{
2 A further increase in the welding speed led to pronounced welding defects.
}

It should be emphasized that all microstructural observations and examinations of mechanical properties in this work were conducted on the postweld heattreated samples, i.e., the as-welded material condition was not considered in the present study.

\subsection{Microstructural Observations}

The microstructural observations were performed using optical microscopy, electron backscatter diffraction (EBSD), and transmission electron microscopy (TEM).

For optical observations, the microstructural specimens were prepared by a mirror-polishing using conventional mechanical-polishing technique, and then chemically etched in Keller's reagent. A suitable surface finish for EBSD and TEM were obtained using electropolishing in a solution of $25 \%$ nitric acid in methanol. Particular care was undertaken during machining of the TEM specimens from the areas of interest.

EBSD analysis was conducted using an FEI Quanta 600 field-emission-gun scanning electron microscope (FEG-SEM) equipped with TSL OIM ${ }^{\mathrm{TM}}$ software operating at the accelerated voltage of $30 \mathrm{kV}$. Depending on a scale of particular microstructure, EBSD scan step size was ranged from 0.2 to $5 \mu \mathrm{m}$. To improve reliability of EBSD data, small grains comprising three or fewer pixels were automatically removed from the acquired maps using the standard grain-dilation option of the TSL software. Furthermore, to eliminate spurious boundaries caused by orientation noise, a lower-limit boundary misorientation cut-off of $2^{\circ}$ was applied. A $15^{\circ}$ criterion was employed to differentiate low-angle boundaries (LABs) from high-angle boundaries (HABs). Grain size was quantified by using the grain-reconstruction approach [113], i.e., converting each grain to a circle of equivalent area and calculating the associated circle-equivalent diameter.

TEM observations were performed using JEM2100EX transmission electron microscope operating at $200 \mathrm{kV}$. In the TEM micrographs shown throughout the manuscript, the TEM specimens were typically tilted to align the incident electron beam with a $\langle 100\rangle$ zone axis in order to enhance the contrast associated with the second-phase particles.

\subsection{Residual Stress Measurements}

Residual stress components, both along the transverse and normal directions, were measured on the weld cross section, by X-ray diffraction (XRD) tech- 
nique using PROTO-LXRD diffractometer and the $\sin ^{2} \psi$ method [114].

To avoid undesirable influence of the stresses generated during grinding and polishing steps of the sample preparation procedure, the measurements were carried out on an electropolished surface. The employed electropolishing procedure was the same as that used for the EBSD and TEM sample preparation.

A cobalt target and accelerated voltage of $25 \mathrm{kV}$ were used to produce X-ray beam with a wavelength of $0.179026 \mathrm{~nm}$. A round collimator with $1 \mathrm{~mm}$ radius and $11 \psi$-off set angles in the range of maximum $\pm 33^{\circ}$ were employed.

The stresses were calculated from the strains of the $\{311\}$ Bragg reflection at $148.9^{\circ}$ Bragg angle, assuming X-ray elastic constants of $S_{1}^{(h k l)}=4.58 \times 10^{-6} \mathrm{MPa}^{-1}$ and $1 / 2 S_{2}^{(h k l)}=18.45 \times 10^{-6} \mathrm{MPa}^{-1}$.

To examine the distribution of the residual stresses on the weld cross section, the measurements were performed on a rectangular grid at equally spaced points, $1 \mathrm{~mm}$ distance in both the normal and transverse directions, encompassing both the entire weld and the base material regions. For each point, 10 measurements with $1 \mathrm{~s}$ exposure time were performed.

\subsection{Mechanical Tests}

An examination of mechanical properties of the weldments included microhardness measurements, transverse tensile tests and transverse fatigue tests.

To provide a broad view of microstructure distribution within the welds, microhardness profiles were measured across the weld midthickness. Vickers microhardness data were obtained by applying a load of $200 \mathrm{~g}$ with a dwell time of $10 \mathrm{~s}$, using a Wolpert 402MVD microhardness tester.

The tensile specimens were machined perpendicular to the welding direction, and were centered along the weld line. The specimens had a gauge section of $30 \mathrm{~mm}$ in length and $7 \mathrm{~mm}$ in width, and included all characteristic microstructural zones generated during friction-stir welding. The upper and lower surfaces of the specimens were mechanically polished to achieve a uniform thickness and remove the surface defects. For comparative purposes, appropriate tensile specimens were also machined from the base material ${ }^{3}$. The

\footnotetext{
3 Taking into an account the initial T6 heat treatment, the total aging time of the parent-material section of the aged specimens was 16 hours. Accordingly, the tensile and fatigue specimens machined from the base material were also artificially aged for 16 hours.
}

Table 1. Statistics of fatigue test

\begin{tabular}{c|c|c|c}
\hline \multirow{2}{*}{$\begin{array}{c}\text { Amplitude } \\
\text { stress, MPa }\end{array}$} & \multirow{2}{*}{$\begin{array}{c}\text { Maximal } \\
\text { cyclic } \\
\text { stress, MPa }\end{array}$} & \multicolumn{2}{|c}{$\begin{array}{c}\text { Number of tested speci- } \\
\text { mens }\end{array}$} \\
\cline { 3 - 4 } & $\begin{array}{c}\text { Base } \\
\text { material }\end{array}$ & $\begin{array}{c}\text { Welded } \\
\text { material }\end{array}$ \\
\hline 67.5 & 150 & 2 & 5 \\
\hline 72 & 160 & 3 & 3 \\
\hline 76.5 & 170 & 2 & 4 \\
\hline 81 & 180 & 3 & 2 \\
\hline 85.5 & 190 & 3 & 3 \\
\hline 90 & 200 & - & 3 \\
\hline 94.5 & 210 & - & 3 \\
\hline 99 & 220 & 3 & 3 \\
\hline 108 & 240 & 3 & 3 \\
\hline
\end{tabular}

Note: The amplitude stress $\sigma_{\mathrm{a}}$ was calculated as $\sigma_{\mathrm{a}}=0.5\left(\sigma_{\max }-\right.$ $\left.\sigma_{\min }\right)$, where $\sigma_{\max }$ and $\sigma_{\min }$ are maximal and minimal stress of a loading cycle, respectively.

tension tests to failure were conducted at an ambient temperature and a constant cross-head velocity corresponding to a nominal strain rate of $10^{-3} \mathrm{~s}^{-1}$. An Instron 300LX universal testing machine was used for the tests. Two tensile specimens were tested for each material condition.

To evaluate fatigue behavior of the welds, dogbone-shaped specimens were machined perpendicular to the welding direction. The fatigue specimens were also centered along the weld line, had a gauge section of $30 \mathrm{~mm}$ in length and $8 \mathrm{~mm}$ in width, and included all characteristic friction-stir welding zones. To achieve a uniform thickness and to prevent the potential effect of surface defects, both the top and bottom surfaces of the specimens were mechanically polished to a final 2400 grit emery paper. On the other hand, the lateral surfaces of the fatigue specimens were produced by electrical-discharge machining and thus had a relatively high roughness. For the aid of comparison, appropriate specimens were also machined from the base material, using the same preparation procedure. The fatigue tests were conducted using an Instron 8801 servo hydraulic testing system, which operated at ambient temperature in a load control mode. A sinusoidal load-time function with a frequency of $50 \mathrm{~Hz}$ and a maximum-to-minimum load ratio of $R=0.1$ was used. The total statistics of the fatigue tests is summarized in Table 1. Statistical analysis of the test results was carried out in accordance with ASTM E 739-91 standard. Fracture surface was examined with the FEI Quanta 600 FEG-SEM. Other details on the fatigue tests can be found elsewhere [115].

PHYSICAL MESOMECHANICS Vol.23 No. 52020 

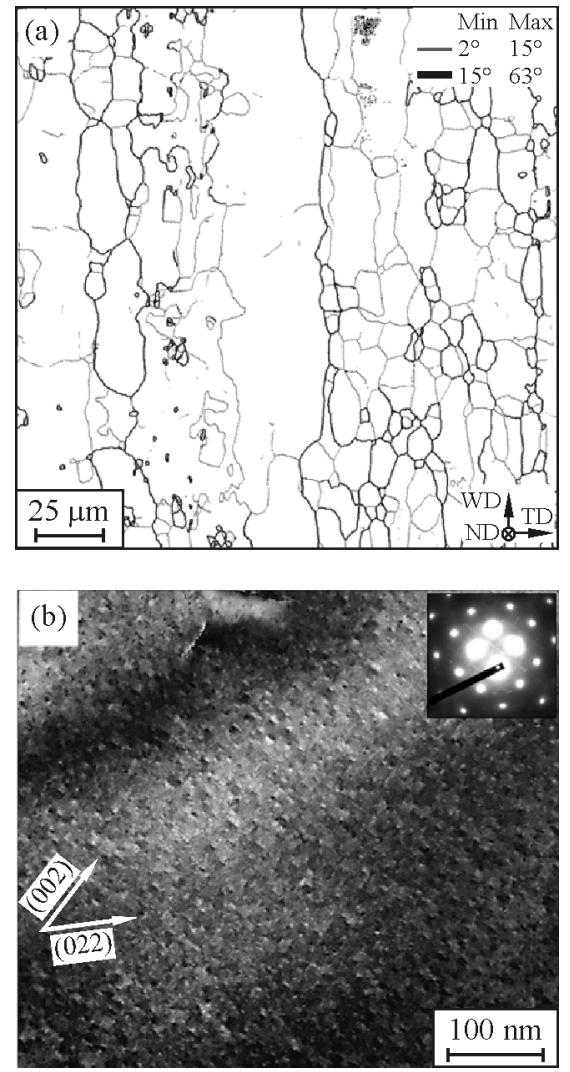

Fig. 1. Microstructure of base material: EBSD grainboundary map (a) and TEM image (b). LABs and HABs are depicted as gray and black lines, respectively (a); the insert in the top right corner shows diffraction pattern (b).

\section{OPTIMIZATION OF FRICTION-STIR WELDING PROCESS}

As suggested in Sect. 1.2, friction-stir welding of heat-treatable aluminum alloys can be optimized by using a combination of high welding temperatures and high cooling rate. This should result in complete particle dissolution in the stir zone but should inhibit the particle coarsening in the heat-affected zone. Accordingly, the postweld aging should result in relatively uniform reprecipitation of strengthening dispersoids in the welded material and thus efficiently recover its strength. In the present section, a reliability of this approach was evaluated. To this end, microstructural changes occurring in various weld zones were analyzed and related with mechanical properties.

\subsection{Base Material}

The microstructure of the base material is shown in Fig. 1. The grain structure was dominated by the coarse elongated grains which contained developed LAB substructure (Fig. 1a). Remarkably, crystallographic axes $\langle 100\rangle$ and $\langle 111\rangle$ of the grains were aligned with prior-extrusion axis (not shown) thus representing a typical extrusion texture. It is likely therefore that the grain structure was primarily associated with the preliminary hot extrusion process described in Sect. 2.1.

On the other hand, the subsequent T6 tempering resulted in high density of nanoscale dispersoids evenly distributed in grain interior (Fig. 1b). The precipitates often had a characteristic coffee-bean contrast reflecting a coherent relationship with aluminum matrix. The revealed precipitation pattern was broadly similar to that is usually observed in the peak-aged $6 x x x$ alloys [e.g. 116, 117]. Specifically, it was dominated by the needle-shaped $\beta^{\prime \prime}$ dispersoids but also
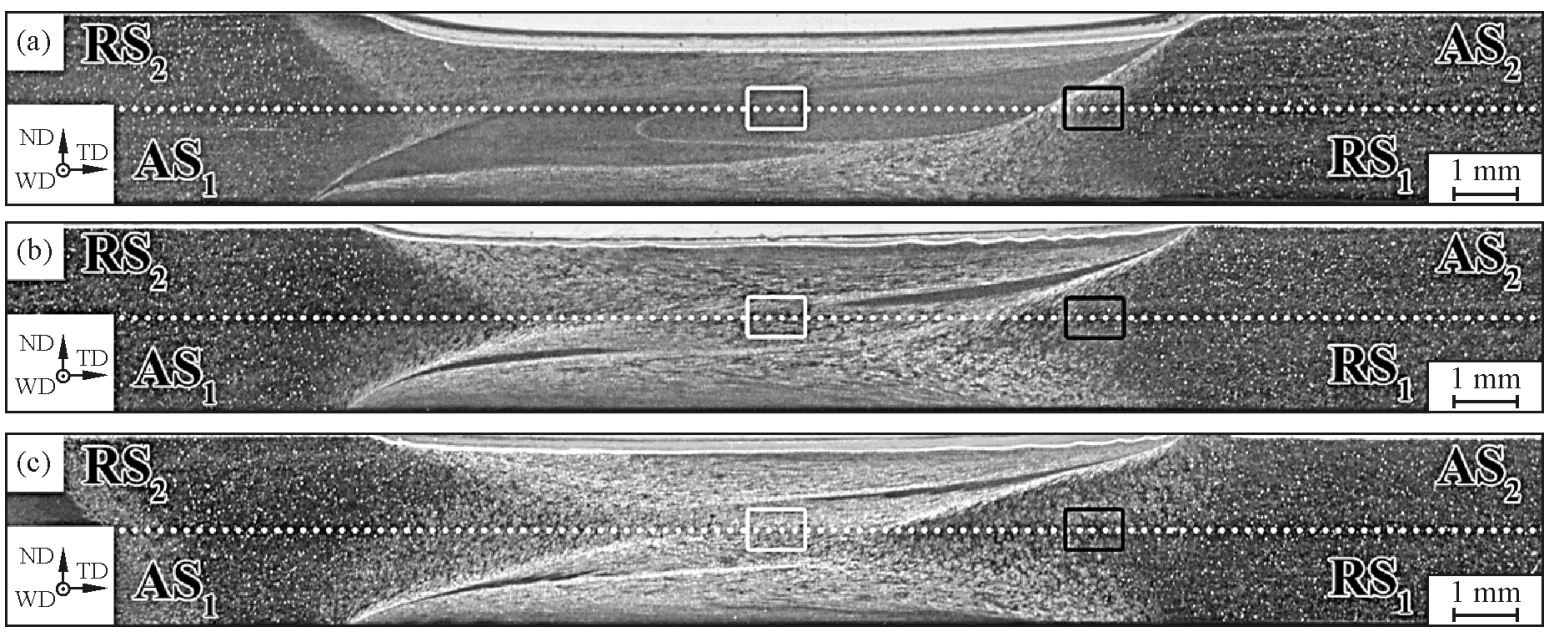

Fig. 2. Low-magnification overview of transversal cross-sections of the welds produced at the tool travel speeds of 125 (a), 380 (b) and $760 \mathrm{~mm} / \mathrm{min}(\mathrm{c}) . \mathrm{AS}_{1}\left(\mathrm{AS}_{2}\right)$ and $\mathrm{RS}_{1}\left(\mathrm{RS}_{2}\right)$ denote the advancing and retreating sides at the first (second) FSW pass, respectively. The while dotted lines indicate the microhardness profiles shown in Fig. 3. The white and black rectangles show the approximate locations of EBSD maps and TEM images given in Figs. 4 to 6. 


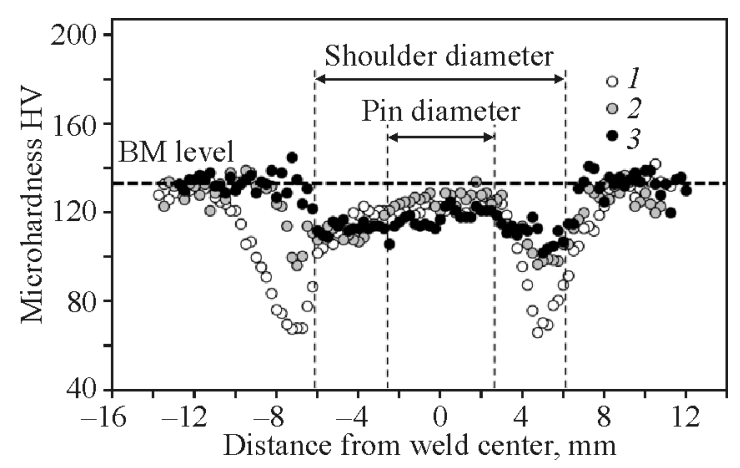

Fig. 3. Effect of welding speed on microhardness profiles measured across transverse cross sections of the postweld aged joints: 125 (1), 380 (2), $760 \mathrm{~mm} / \mathrm{min}$ (3). The horizontal dotted line shows the mean microhardness of base material (BM).

included a minor fraction of lath-shaped $Q^{\prime}$ particles. It is also worth noting in this regard that the metastable $\beta^{\prime \prime}$ phase is well accepted to be the main strengthening precipitate in the peak-aged $6 \mathrm{xxx}$ alloys.

\subsection{Low-Magnification Overview of Welds}

Low-magnification optical images of the cross-sectioned welds produced at different welding speeds are summarized in Fig. 2. In all cases, the revealed macroscale structures were more or less similar in appearance. Specifically, a distinct stir zone with clear over- lap between two friction-stir welding passes (i.e., a double-side friction-stir welding) was seen. It was evident that the welds contained no macroscale defects, including the "kissing bond" defect.

To evaluate microstructure distribution within the welds, microhardness profiles were measured along the dotted lines in Fig. 2, with the obtained results being summarized in Fig. 3. For clarity, the shoulder and probe diameters were also indicated in the microhardness profiles. To a first approximation, the probe diameter delineates the stir zone whereas the shoulder diameter shows the heat-affected zone.

From Fig. 3, it was clear that friction-stir welding resulted in essential material softening. Moreover, this effect was very sensitive to the welding speed. Particularly, the weld produced at the lowest welding speed of $125 \mathrm{~mm} / \mathrm{min}$ exhibited the most pronounced softened zone. In accordance with the literature [e.g. 118-121], the softest region was located near the shoulder edge. On the other hand, an increase in the welding speed provided a gradual elimination of the softening effect thus leading to a smoothing of the microhardness profiles. This encouraging result was obviously in the line with one of the proposed idea.

As expected, the postweld aging essentially restored material strength in the stir zone (Fig. 3). This also agreed well with previous reports [e.g. 109]. Remar-
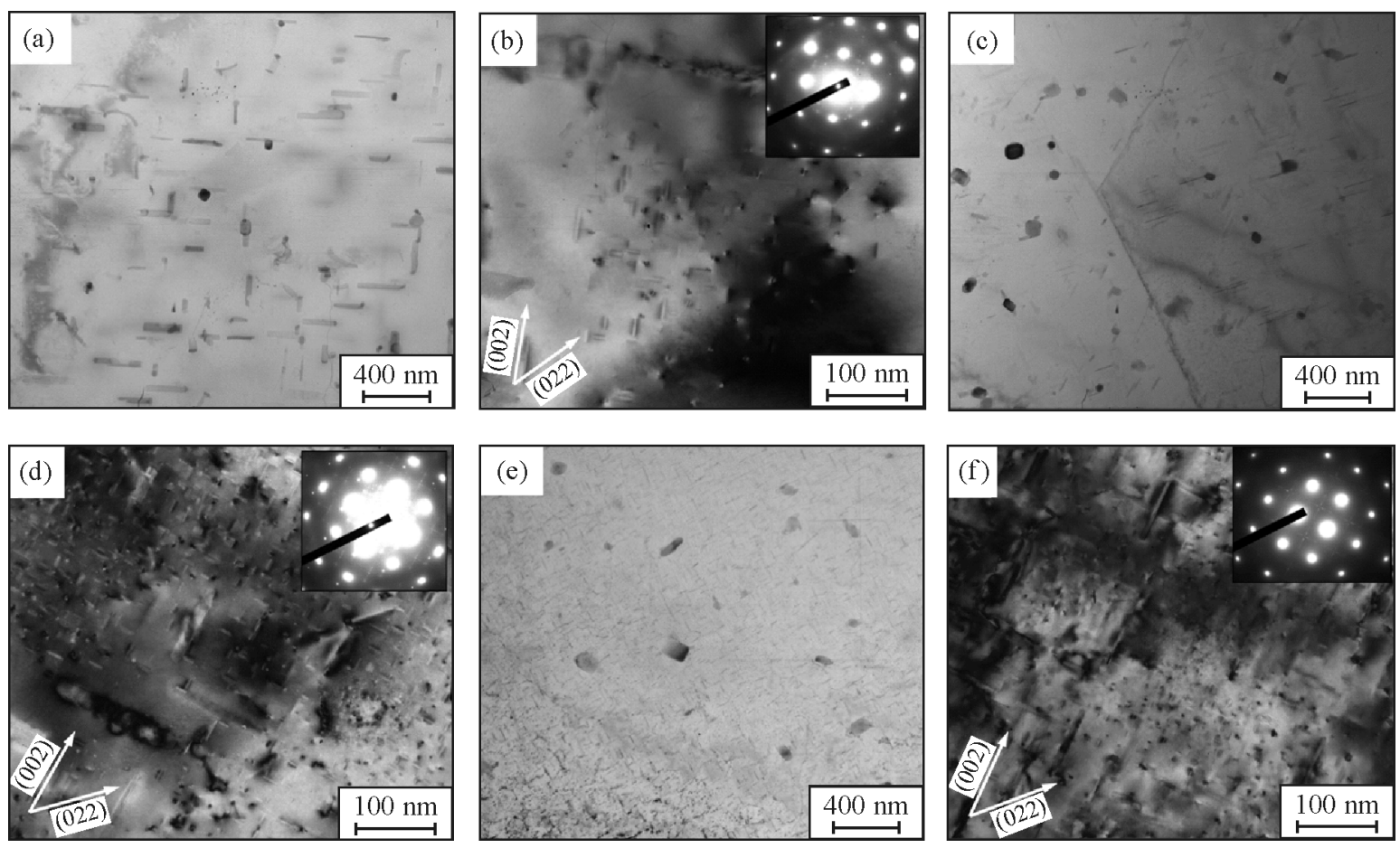

Fig. 4. TEM images showing second-phase particles in the heat-affected zone of the friction-stir welds produced at the welding speed of $125(\mathrm{a}, \mathrm{b}), 380(\mathrm{c}, \mathrm{d})$, and $760 \mathrm{~mm} / \mathrm{min}(\mathrm{e}, \mathrm{f})$. The inserts in the top right corners of (b, d, and f) show diffraction patterns. 

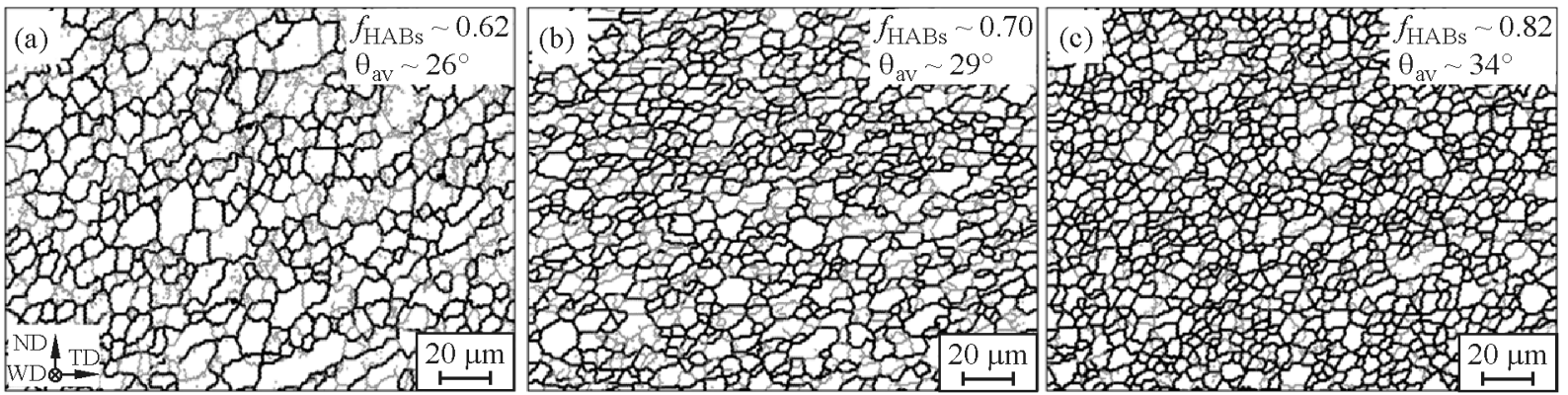

Fig. 5. EBSD grain-boundary maps showing grain structures evolved in central sections of the welds produced at the welding speed of 125 (a), 380 (b), and $760 \mathrm{~mm} / \mathrm{min}$ (c). LABs and HABs are depicted as gray and black lines, respectively. The $f_{\mathrm{HABs}}$ and $\theta_{\mathrm{av}}$ in the inserts in the top right corners indicate the HABs fraction and the average misorientation, respectively.

kably, all studied welds showed nearly the same microhardness level. Another interesting issue was the observation that the recovered microhardness in the stir zone was somewhat lower than that in the base material, despite the exactly the same aging treatment was applied (i.e., soaking at $160^{\circ} \mathrm{C}$ for 8 hours). This interesting effect is discussed in Sect. 3.4.

\subsection{Heat-Affected Zone}

The microhardness measurements discussed in the previous section revealed two microstructural regions of particular interest, viz. the heat-affected zone and the stir zone. The microstructures evolved in these areas were studied by TEM and EBSD techniques and the obtained results are considered in this and the following sections.

Typical TEM images of the microstructures evolved in the heat-affected zones are summarized in Fig. 4. As expected, the weld produced at the lowest welding speed was characterized by the relatively coarse rod-shaped particles (Fig. 4a). Considering the specific morphology of these precipitates as well as their alignments with $\langle 100\rangle$ direction (not shown), they could be interpreted as the $\beta^{\prime}$ phase. It is well accepted that these particles originate from a growth of the $\beta^{\prime \prime}$ dispersoids. On the other hand, the volume fraction of the original $\beta^{\prime \prime}$ dispersoids was found to essentially decrease (compare Figs. $1 \mathrm{~b}$ and $4 \mathrm{~b}$ ). These observations presumably evidenced a coarsening of the $\beta^{\prime \prime}$ precipitates occurring during weld thermal cycle, in full accordance with the literature reviewed in Sect. 1.2.

In accordance with expectations, an increase of the welding speed resulted in gradual disappearance of the relatively coarse $\beta^{\prime}$ phase (Figs. $4 \mathrm{c}$ and $4 \mathrm{e}$ ) but retention of the original $\beta^{\prime \prime}$ precipitates (Figs. $4 d$ and $4 \mathrm{f})$. These results agreed well with the observed smoothing of the microhardness profiles (Fig. 3) and perhaps evidenced an inhibition of the particle coarsening process.

\subsection{Stir Zone}

EBSD maps showing the stir zone microstructures evolved in different welds are summarized in Fig. 5. As expected, friction-stir welding gave rise to drastic a grain refinement (compare Figs. 1a and 5). In all cases, the friction-stir welding-induced microstructures were comprised by relatively fine nearly-equiaxed grains; HAB fraction was measured to vary from $\sim 60$ to $80 \%$ (Fig. 5). Such grain structures are often

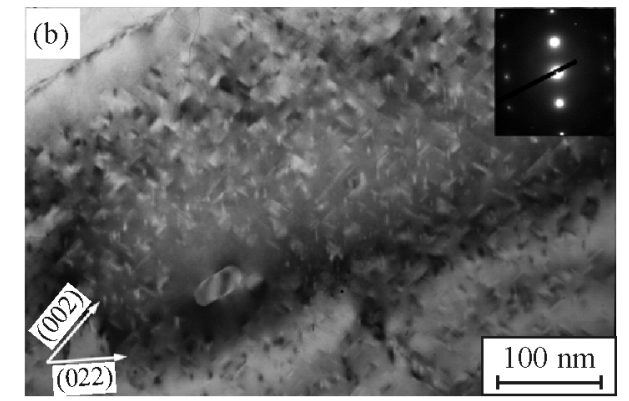

Fig. 6. TEM images showing second-phase particles in the central section of friction-stir welds produced at the welding speed of 125 (a) and $760 \mathrm{~mm} / \mathrm{min}$ (b). The inserts in the top right corner show diffraction patterns. 

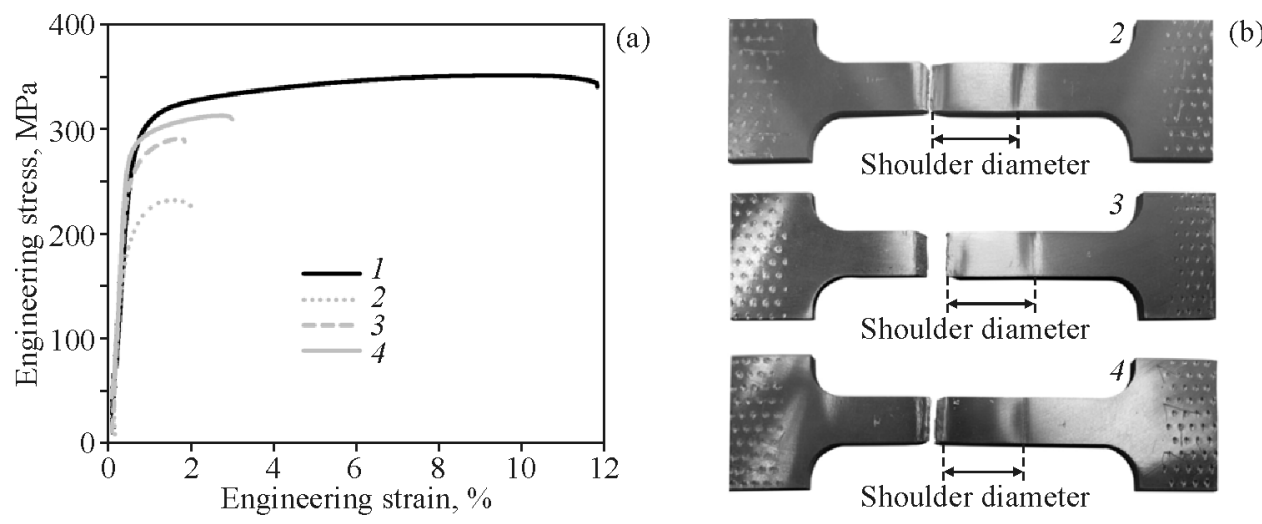

Fig. 7. Typical deformation diagrams (a) and appearance of the failed specimens (b) showing the effect of welding speed on transverse tensile properties of aged welds: base material (1), welding speed of 125 (2), 380 (3), and $760 \mathrm{~mm} / \mathrm{min}$ (4).

observed in friction-stir welded aluminum alloys being usually attributed to a continuous recrystallization operating during the welding process [122-124]. It is interesting to note than the grain refinement effect became more pronounced with the welding speed (Fig. 5). This observation was in the line with shortening of the weld thermal cycle at high welding speeds which should inhibit microstructural coarsening occurring during weld cooling cycle [122].

Typical TEM images of the stir zone microstructures are given in Fig. 6. It is clear that the postweld aging promoted reprecipitation of the strengthening dispersoids. In terms of morphology, size and even coffee-bean contrast, the reprecipitated particles were broadly similar to that found in the base material, and, perhaps, were also composed by the $\beta^{\prime \prime}$ and $Q^{\prime}$ phases. On the other hand, from comparison of Figs. $1 \mathrm{~b}$ and 6 , it seems that the volume fraction of the stir zone precipitates was somewhat lower than that in the base material. This perhaps explains a subtle difference in strength between those microstructural regions seen in

Table 2. Effect of welding speed on static mechanical properties of aged welds

\begin{tabular}{l|c|c|c|c}
\hline $\begin{array}{c}\text { Material } \\
\text { condition }\end{array}$ & $\begin{array}{c}\text { Yield } \\
\text { strength, } \\
\mathrm{MPa}\end{array}$ & $\begin{array}{c}\text { Joint effi- } \\
\text { ciency, \% }\end{array}$ & $\begin{array}{c}\text { Ducti- } \\
\text { lity, \% }\end{array}$ & $\begin{array}{c}\text { Failure } \\
\text { location }\end{array}$ \\
\hline Base material & 290 & - & 11 & - \\
\hline $\begin{array}{l}\text { FSW at } \\
125 \mathrm{~mm} / \mathrm{min}+ \\
\text { aging }\end{array}$ & 190 & 66 & 1.6 & \\
\cline { 1 - 2 } $\begin{array}{l}\text { FSW at } \\
380 \mathrm{~mm} / \mathrm{min}+\end{array}$ & 260 & 90 & 1.4 & $\begin{array}{c}\text { Sof- } \\
\text { tened } \\
\text { region }\end{array}$ \\
\cline { 1 - 2 } $\begin{array}{l}\text { FSW at } \\
760 \mathrm{~mm} / \mathrm{min}+\end{array}$ & 280 & 97 & 3.3 & \\
aging & & & & \\
\hline
\end{tabular}

the microhardness profile (Fig. 3). If so, this interesting effect deserves an explanation.

Assuming that the welding temperature in the stir zone was high enough for the particle dissolution, it is necessary to emphasize than the air-cooling conditions of the weld cooling cycle were likely different from those associated with the water quenching. If so, a partial reprecipitation of the dispersoids could occur, as noted in Sect. 1.2. This should reduce a supersaturation degree of the solid solution, and, accordingly, decrease a driving force for the particle nucleating during postweld aging. As a result, the population density of the stir zone dispersoids was lower than that in the base material.

\subsection{Tensile Behavior of Aged Welds}

The effect of welding speed on transverse tensile behavior of the aged welds is shown in Fig. 7. For comparative purpose, the deformation diagram of the base material was also given in Fig. 7a. In all cases, the duplicate test demonstrated very similar results and thus only single data set was presented. The relevant mechanical properties were summarized in Table 2. An appearance of the failed specimens is shown in Fig. 7b; for clarity, the shoulder diameter was indicated in the figure.

The tensile tests also revealed the material softening occurring during friction-stir welding (Fig. 7a), thus being in the line with microhardness measurements. Also in agreement with the microhardness experiment, an increase in the welding speed promoted a gradual restoration of material strength (Fig. 7a). Specifically, the weld produced at the speed of $760 \mathrm{~mm} / \mathrm{min}$ exhibited a joint efficiency of $97 \%$ (Table 2).

Another remarkable observation was the relatively low ductility of the welds (Fig. 7a, Table 2). As follows 
from Fig. 7b, this effect was associated with strain localization at the shoulder edge region (i.e., virtually in the heat-affected zone) during the tensile tests. This agrees well with measurements of strain distribution in tensioned $6 \mathrm{xxx}$ friction-stir welds $[111,112]$. It is worth noting that the increase in the welding speed improved ductility somewhat (Table 2).

All the above observations could be explained in the terms of particle coarsening occurring in the heataffected zone during friction-stir welding and gradual elimination of this effect at high welding speeds.

\subsection{Preliminary Conclusions}

From the results considered above, the following conclusions could be drawn.

An increase in the welding speed during frictionstir welding tends to inhibit precipitation coarsening occurring in the heat-affected zone. This improves the weld-scale uniformity of the particle distribution precipitated during subsequent aging and thus essentially restores strength characteristics of the welded material. Specifically, the weld produced with the highest employed welding speed of $760 \mathrm{~mm} / \mathrm{min}$ exhibited a joint efficiency of $97 \%$.

Despite a significant progress achieved in recovering of the weld strength, the weld ductility remained very low. This effect could be attributed to preferential strain localization in the softest microstructural region (i.e., the heat affected zone) during transverse tensile tests.

In the peak-aged condition, the microhardness of the stir zone material was found to be somewhat lower than that of the base material. This effect was associated with the relatively low cooling speed inherent to the weld cooling cycle which could result in partial reprecipitation of dispersoids. This should reduce the precipitation potential of the welded material during subsequent aging and thus slow down the precipitation kinetics.

\section{SUPPRESSION OF ABNORMAL GRAIN GROWTH DURING T6 TEMPERING}

\subsection{Effect of T6 Tempering on Microstructure and Mechanical Properties}

As shown above, the optimization of friction-stir welding process enabled to recover efficiently the weld strength but the weld ductility remained relatively low. Attempting to overcome this problem, the produced welds were undergone the standard T 6 treatment. The details of the tempering procedure are described in Sect. 2.1. It is important to emphasize that the T6 tempering was applied only to the optimized welds, i.e., those produced at the tool rotational speed of $1100 \mathrm{rpm}$ and the welding speed of $760 \mathrm{~mm} / \mathrm{min}$.

As follows from EBSD map in Fig. 8a, the microstructure produced in the stir zone after T6 tempering was dominated by $\mathrm{mm}$-scale irregular-shaped grains. Importantly, the annealed material also contained a minor fraction of survived fine grains (an example is arrowed). The bimodality of the evolved microstructure as well as its exceptionally coarse-grained nature presumably evidenced an abnormal character of the grain growth. As shown in Sect. 1.3, this phenomenon is often observed during high-temperature annealing of friction-stir welded aluminum alloys.

Despite the catastrophic grain growth occurred in the stir zone, the material microhardness was fully recovered and uniformly distributed across the weld (Fig. 8b). This result was obviously attributable to the complete precipitation of the strengthening $\beta^{\prime \prime}$ phase during aging step of the T6 treatment. As a result, the joint efficiency of the tempered weld achieved $\sim 100 \%$ (Fig. 9a).

The weld ductility was also improved but was still lower than that of the base material (Fig. 9a). From Fig. 9b, it was evident that the limited ductility of the tempered weld was associated with strain localization
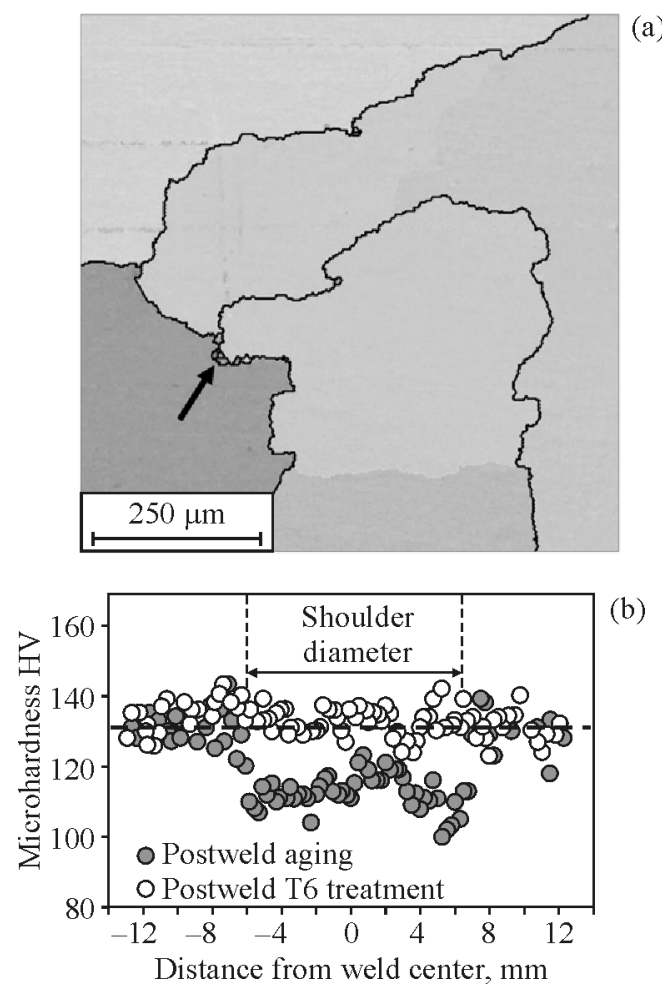

Fig. 8. Effect of the postweld T6 tempering treatment on stir zone microstructure (a) and microhardness distribution (b). 

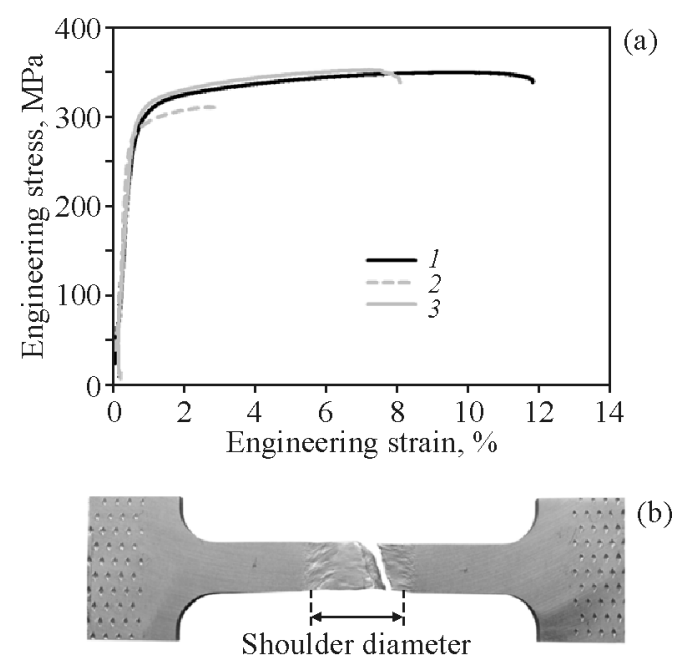

Fig. 9. Effect of the postweld T6 tempering on tensiledeformation diagrams (a) and appearance of the failed specimen (b). Base material (1), postweld aging (2), postweld T6 (3).

within the stir zone, most likely due to the abnormally coarse-grained microstructure evolved in this region (Fig. 8a).

\subsection{Effect of Prestraining on Annealing Behavior}

As suggested in Sect. 1.3, the prestrain rolling may suppress the abnormal grain growth. This idea was based on the activation of recrystallization process instead of the abnormal grain growth during subsequent annealing, which should promote a competitive character of microstructural coarsening. To examine a reliability of this approach, the produced welds were cold rolled prior to the postweld $\mathrm{T} 6$ tempering. The details of the rolling procedure are explained in Sect. 2.3. It is also should be noted that the prestraining was also applied only to the optimized welds.

The effect of the prestraining on subsequent annealing behavior of the welded material is summarized in Figs. 10 and 11. From comparison of Figs. 10 and $8 \mathrm{a}$, it is clear that the prestrain rolling resulted in substantial microstructural refinement, i.e., the abnormal grain growth was suppressed. As expected, this effect became more pronounced at higher rolling reductions (compare Figs. 11a and 11b).

Of particular interest was the observation that the grain-refinement efficiency of the prestraining was
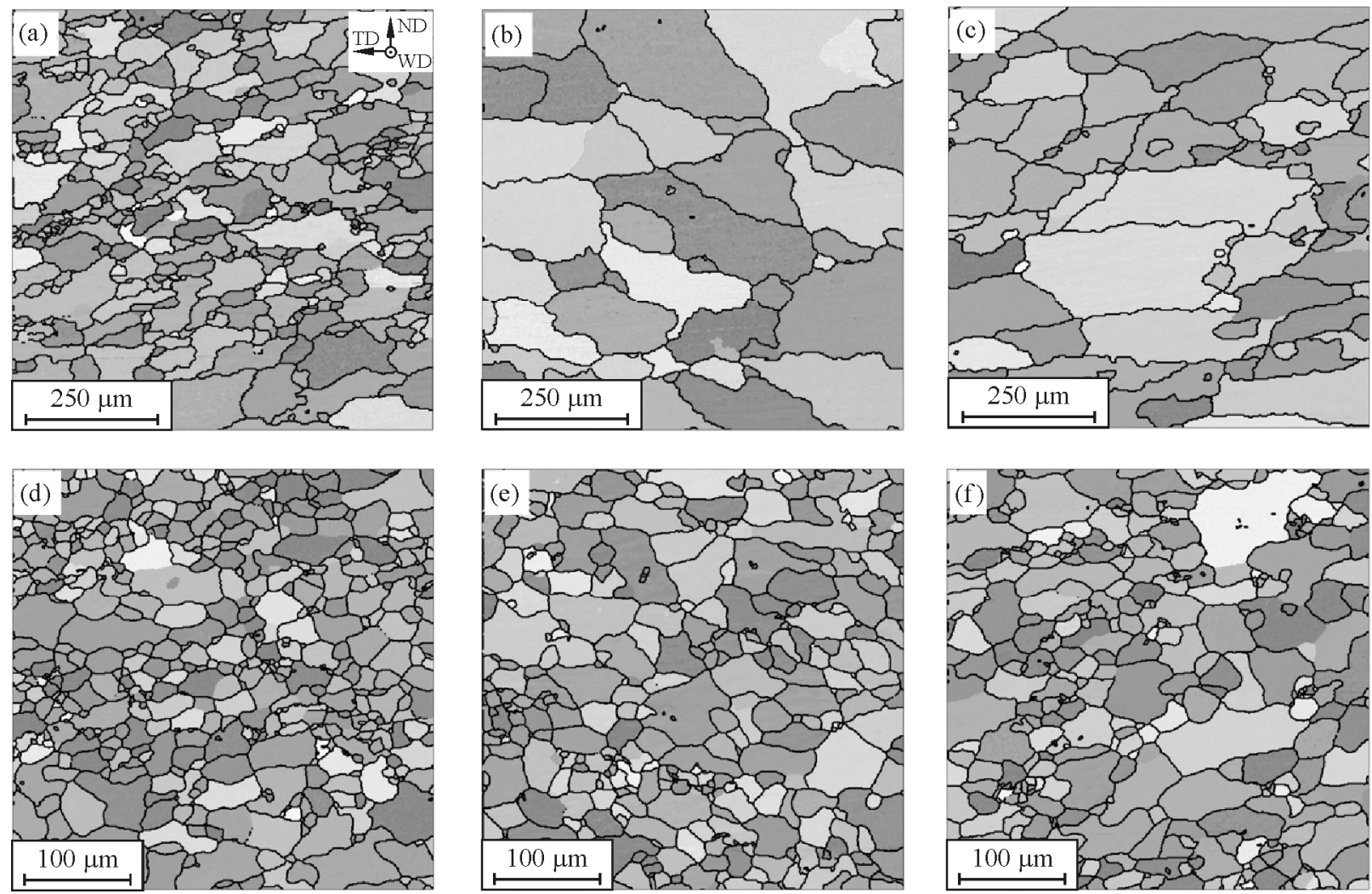

Fig. 10. EBSD maps showing microstructures produced in the central section of stir zone of the T6-tempered welds as function of prestrain path: $10 \%$ rolling along the welding direction (a), $10 \%$ rolling at $45^{\circ}$ to the welding direction (b), $10 \%$ rolling along transverse direction (c), $20 \%$ rolling along the welding direction (d), $20 \%$ rolling at $45^{\circ}$ to the welding direction (e), and $20 \%$ rolling along the transverse direction (f). In the maps, HABs are depicted as solid black lines. The reference frame for all maps is shown in (a). Note difference in scales. 

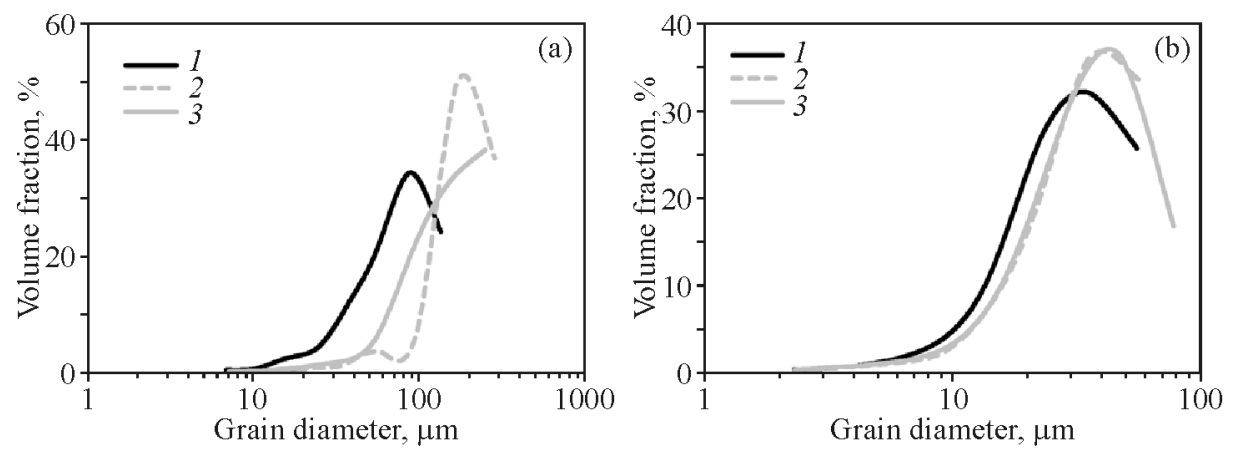

Fig. 11. Grain-size distributions measured in the central section of stir zone after prestrain rolling to 10 (a) or $20 \%$ (b) of thickness reduction and subsequent T6 tempering. Rolling along welding direction (1), at $45^{\circ}$ to welding direction (2), along transverse direction (3).

sensitive to the rolling path. This effect was most pronounced after relatively low rolling reduction. Specifically, the smallest grain size was produced after $10 \%$ rolling along the welding direction (Figs. 10a and $11 \mathrm{a})$. With increase in the rolling strain to $20 \%$, however, the anisotropy of the annealing behavior became relatively small (Figs. 10d-10f and 11b).

\subsection{Effect of Prestraining on Tensile Properties of T6 Tempered Welds}

The effect of the prestraining path on tensile behavior of T6 tempered welds is summarized in Fig. 12. The appearance of the failed specimens is shown in Fig. 13.

From Fig. 12, it is clear that the yield strength of all tempered welds was comparable with that of the base material, i.e., the joint efficiency was virtually $100 \%$. As suggested in Sect. 4.1, this result was likely associated with relatively uniform distribution of strengthening dispersoids across the welds.

In contrast, the weld ductility was relatively low (Fig. 12). The welds subjected to the standard T6 tempering without any prestraining exhibited the lowest elongation-to-failure (Fig. 12). As noted in Sect. 4.1,

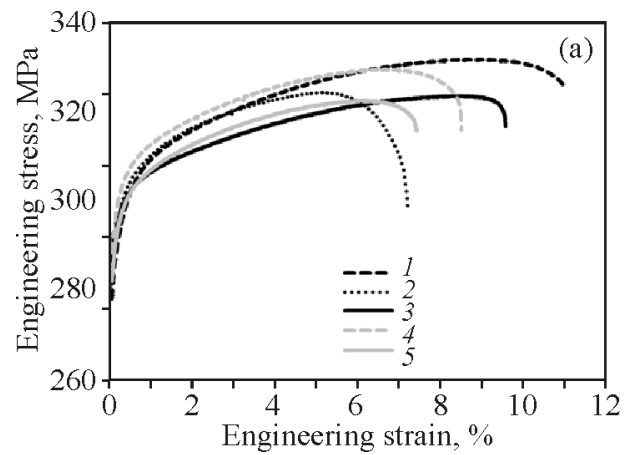

this was presumably due to the abnormal grain growth occurring in the stir zone (Fig. 8a).

The prestraining resulted in essential recovery of the weld ductility (Fig. 12). It is important to emphasize, however, that this effect was very sensitive to the rolling path. Specifically, the welds prerolled to $10 \%$ of strain along the welding direction (Fig. 12a) as well as those rolled to $20 \%$ at $45^{\circ}$ to the welding direction (Fig. 12b) showed the highest elongation-to-failure. As follows from the observations of the deformation relied in the failed specimens (Figs. 13a and 13e), the excellent ductility of these welds was associated with relatively uniform strain distribution. On the other hand, other prestrained specimens exhibited clear evidences of strain localization in either the stir zone (Figs. 13b and 13c), or the base material (Figs. 13d and 13f). Accordingly, the global elongation-to-failure of these weldments was relatively low (Fig. 12). The possible origin of the strain localization is discussed in Sect. 4.6.

\subsection{Effect of Prestraining on Recrystallization Behavior}

The pronounced grain refinement observed in the prestrained material appeared to indicate that the pre-

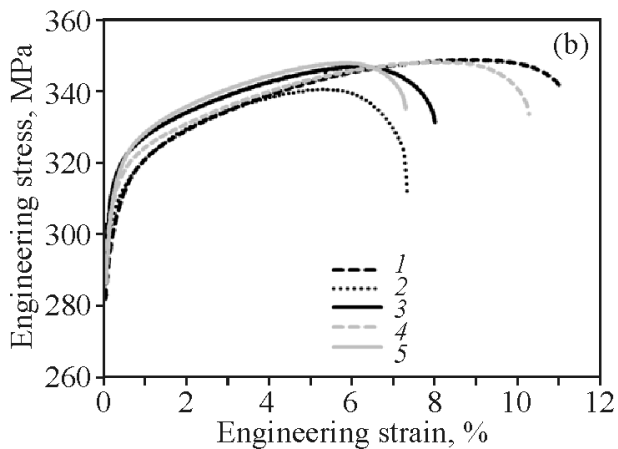

Fig. 12. Tensile behavior of welded material as function of prestrain rolling and subsequent T6 tempering: $10 \%$ rolling (a) and $20 \%$ rolling (b). Base material (1), FSW + T6 (2), FSW + rolling along WD + T6 (3), FSW + rolling at 45 to WD + T6 (4), FSW + rolling along $\mathrm{TD}+\mathrm{T} 6(5)$. 


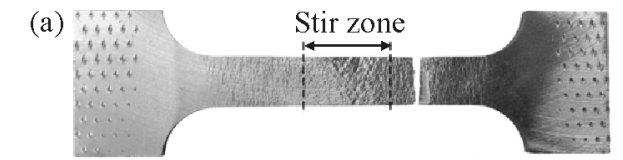

(b)

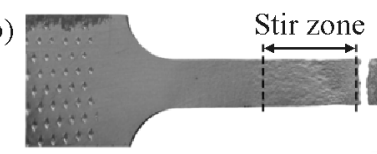

(c)

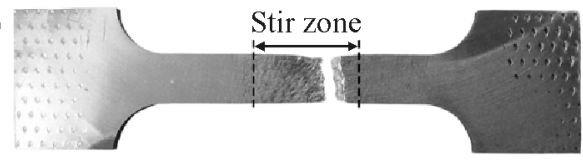

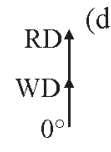
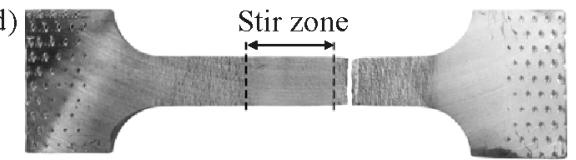

$\mathrm{RD} \uparrow$
$\mathrm{WD}$
$0^{\circ}$
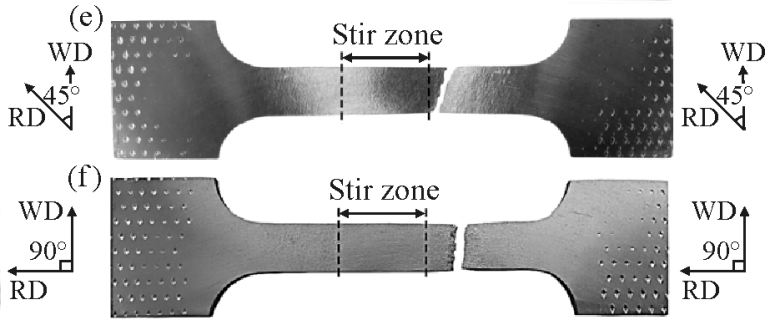

Fig. 13. Appearance of failed tensile specimens as function of prestrain rolling path: $10 \%$ rolling along the welding direction (a), $10 \%$ rolling at $45^{\circ}$ to the welding direction (b), $10 \%$ rolling along transverse direction (c), $20 \%$ rolling along the welding direction (d), $20 \%$ rolling at $45^{\circ}$ to the welding direction (e), and $20 \%$ rolling along the transverse direction (f). Note: RD is rolling direction.

rolled material has indeed experienced a recrystallization instead of the abnormal grain growth during T6 tempering. The possible mechanisms of this phenomenon are discussed in the present section.

It is widely accepted that the recrystallization process is critically influenced by a density of stored dislocations. Specifically, a higher dislocation density achieved after larger preliminary strain enhances the nucleation of recrystallization nuclei and thus results in finer recrystallized grain size. This well-known phenomenon explains well the observed enhancement of the grain-refinement effect with increasing of the prerolling strain from 10 to $20 \%$ of thickness reduction (Figs. 10 and 11).

It is worth noting that the total dislocation density in a deformed polycrystalline material could be divided in two broad groups, i.e., the so-called statistically stored dislocations and the geometrically necessary dislocations [125]. The dislocations belonging to the first group are accumulated by a random mutual trapping whereas those of the second type are generated to accommodate the strain gradients arising between differently deformed grains [125]. Thus, depending on the strain compatibility requirements in a particular microstructure, a nominally equivalent strain may result in different density of the geometrically necessary dislocations. To evaluate this effect in the present

Table 3. Average Taylor factor for different paths of prestrain rolling

\begin{tabular}{l|c}
\hline & $\begin{array}{c}\text { Average } \\
\text { Taylor factor }\end{array}$ \\
\hline Rolling along welding direction & 3.17 \\
\hline Rolling at $45^{\circ}$ to the welding direction & 3.10 \\
\hline Rolling along the transverse direction & 2.95 \\
\hline
\end{tabular}

study, appropriate Taylor factors for three employed rolling directions (i.e., along the welding direction, at $45^{\circ}$ to the welding direction, and along the transverse direction) were calculated from EBSD data of the as friction-stir welded material. The obtained results were summarized in Table 3. It is seen that the highest Taylor factor (and thus the presumably highest density of the geometrically necessary dislocations) was predicted for the rolling along the welding direction.

In addition to the total dislocation density, the recrystallization behavior is also believed to be very sensitive to the orientation spread existing within the
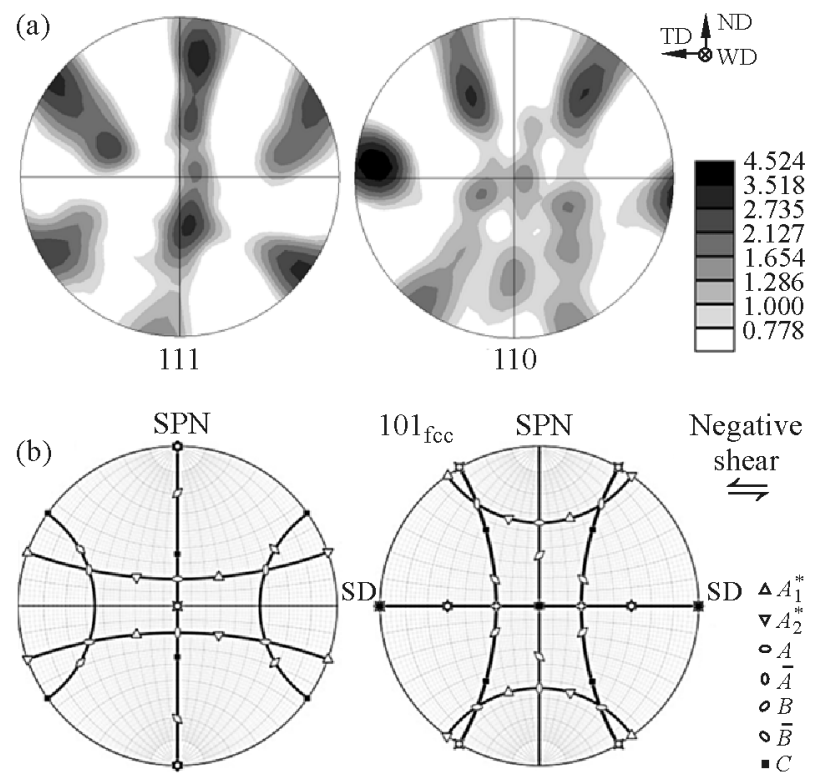

Fig. 14. 111 and 110 pole figures showing texture measured in central section of the stir zone in as-welded condition (a), and ideal simple shear textures expected for facecentered cubic metals (after Fonda et al. [126]) (b). In (b), SD and SPN abbreviate shear direction and shear plane normal, respectively. 

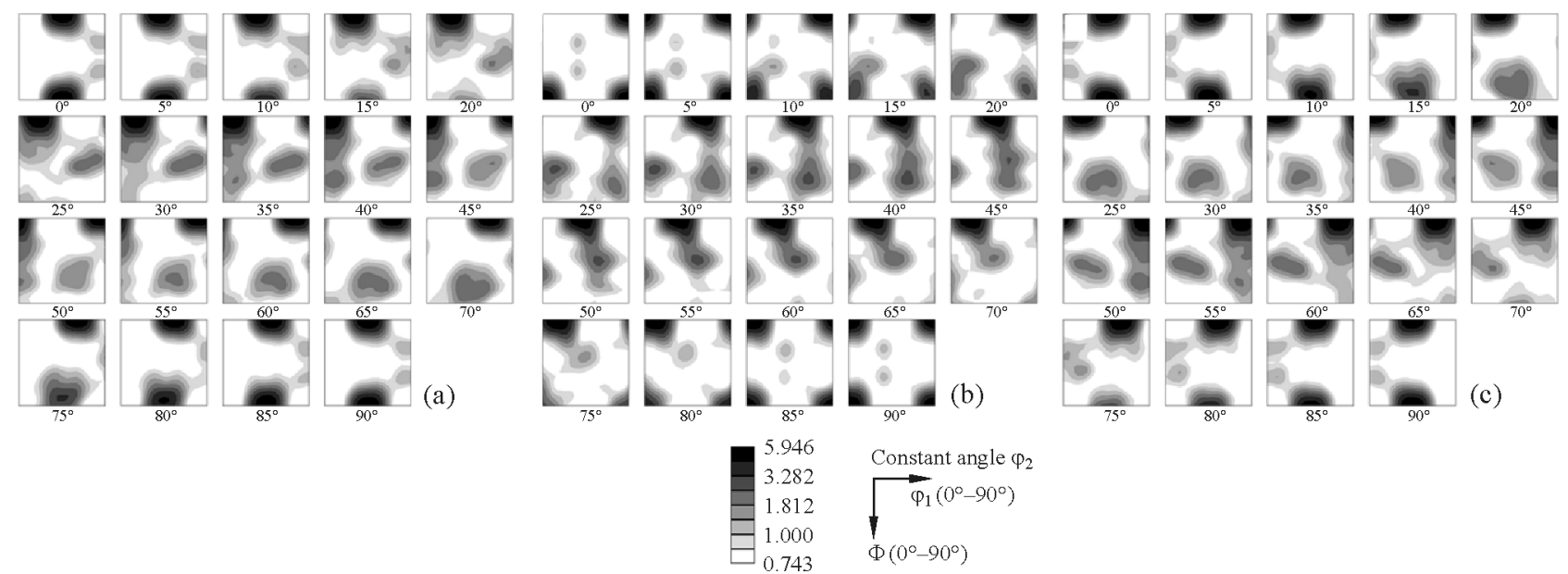

Fig. 15. Orientation distribution functions (ODFs) showing orientation of the stir zone material in the reference frame assuming rolling along welding direction (a), at $45^{\circ}$ to the welding direction (b), and along transverse direction (c).

prestrained grains [77]. It is well established that the orientation gradients stimulate the nucleation process and thus may contribute to refinement of the recrystallized grains. It is believed that the orientation gradients are generated during straining of grains with unstable crystallographic orientations. Such grains are typically split into regions of different crystallographic orientations thus giving rise to the orientation gradients. In contrast, the grains with stable crystallographic orientations are expected to experience a relatively uniform strain and thus no significant orientation gradients are produced.

To evaluate the above effect, the texture of the as friction-stir welded material was examined, as shown in Fig. 14. It was found that the FSW-induced texture (Fig. 14a) was close to the ideal $\{h k l\}\langle 110\rangle$ simple shear fiber (Fig. 14b) [127]. A formation of such texture during friction-stir welding of aluminum alloys has been reported in the literature [e.g. 124]. It is important to note that the texture in Fig. 14 was shown in conventional reference frame for the simple-shear strain mode, which is believed to be dominant during friction-stir welding [126]. To evaluate its stability against the subsequent rolling strain, orientation data were rearranged into the appropriate rolling reference frame and the calculated orientation distribution functions (ODFs) were summarized in Fig. 15.

In the reference frames assuming a rolling along either the welding direction of the transverse direction, the FSW-induced texture was dominated by the $\{001\}\langle 110\rangle$ rotated cube orientation (Figs. 15a and $15 \mathrm{c}$, respectively). This orientation is known to be unstable during cold rolling $[128,129]$. Accordingly, the two above rolling paths are expected to give rise to the considerable orientation spreads within the deformed grains. This should promote grain refinement during subsequent recrystallization. In contrast, the texture of the material rolled at $45^{\circ}$ to the welding direction was rather close to $\{001\}\langle 110\rangle$ cube orientation (Fig. 15b). This orientation is believed to be relatively stable at low rolling reductions [130]. As a result, a relatively coarse-grained structure could be expected in this case.

It was suggested, therefore, that the relatively finegrained structure produced after prestrain rolling along the welding direction (Fig. 11a) was associated with a combined effect of the relatively high Taylor factor (Table 3) and low-stability of the as-FSWed texture (Fig. 15a).

\subsection{Annealing Textures}

In order to provide an additional insight into annealing behavior of the prestrained welds, annealing textures were studied. To this end, orientation data were derived from appropriate EBSD maps in Fig. 10, arranged as 111 and 110 pole figures, and shown in Fig. $16^{4}$.

In all studied cases, the produced textures were relatively weak and diffusive. Nevertheless, from comparison with Fig. 14a, it was clear that the annealing textures originated from a $\sim 25^{\circ}\langle 111\rangle$ rotation of the FSW-induced texture, as exemplified in Fig. 16a. Such texture rotation is well known for recrystallized

\footnotetext{
${ }^{4}$ Due to relatively coarse-grained nature of the microstructures produced after $10 \%$ rolling either at $45^{\circ}$ to the welding direction or along the transverse direction (Figs. 10b and 10c), reliable textural data were difficult to obtain. Therefore, these two material conditions were excluded from consideration.
} 


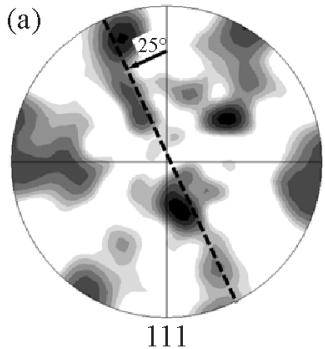

(a)

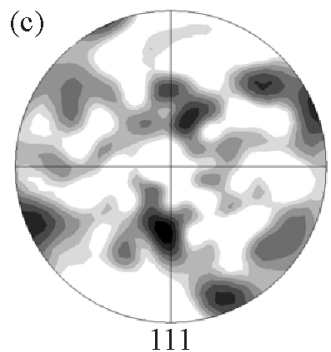

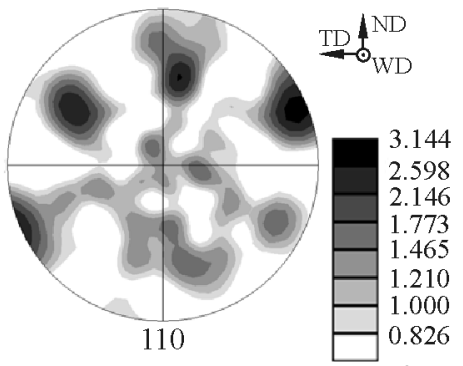
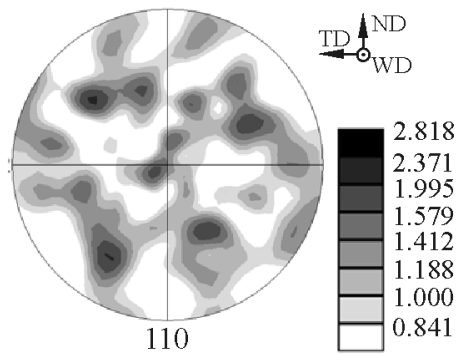

(b)

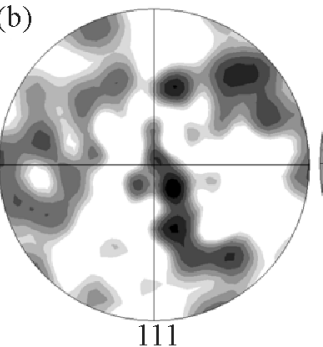

111 (d)

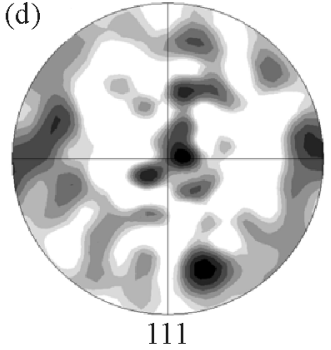

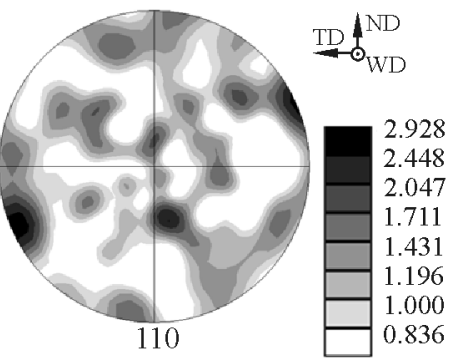

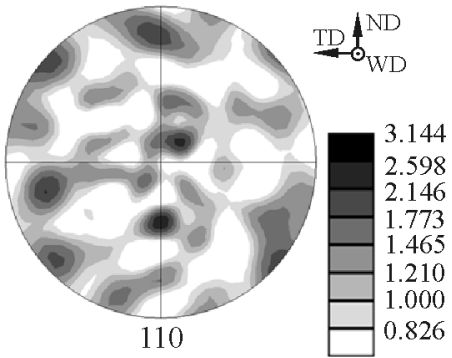

Fig. 16. 111 and 110 pole figures showing textures produced in the central portion of T6-tempered welds as function of pre-strain path: $10 \%$ rolling along welding direction (a), $20 \%$ rolling along the welding direction (b), $20 \%$ rolling at $45^{\circ}$ to the welding direction (c), and $20 \%$ rolling along transverse direction (d). See Sect. 4.5 for details.

aluminum, being usually explained in terms of either the theory of orientation nucleation or the theory of orientation growth [76].

According to the first conception, the recrystallization texture is attributed to the preferred nucleation of grains of particular crystallographic orientation. Such orientations are characterized by a relatively low stored energy and therefore their nucleation is energetically beneficial. To evaluate the applicability of this idea for the present study, grain orientation spread within the as-FSWed microstructure was measured by using the standard options of EBSD software, as shown in Fig. 17. As follows from the figure, the grains with crystallographic orientations close to the final recrys-

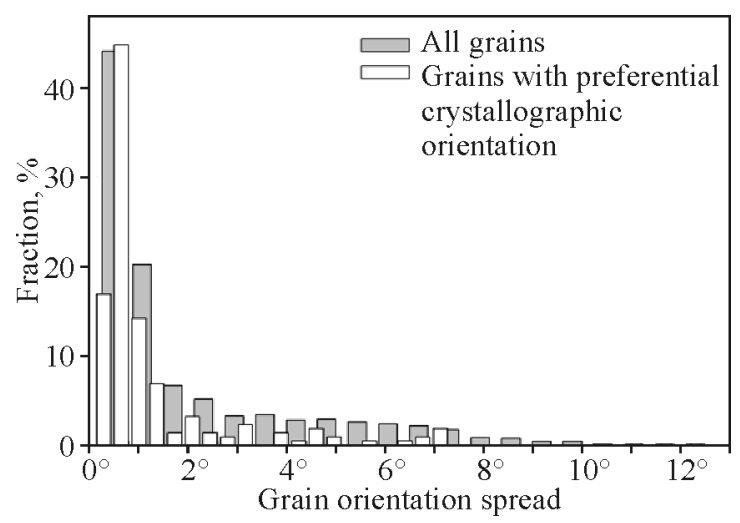

Fig. 17. Analysis of grain orientation spread measured within the grains with preferential crystallographic orientation in the as-welded condition. Note: The preferential crystallographic orientation was defined within $10^{\circ}$ tolerance. See Sect. 4.5 for details. tallization texture had relatively large orientation spread (i.e., a presumably high stored energy). It is unlikely therefore that these grains had an advantage for the recrystallization nucleation. Therefore, the orientation nucleation theory could not explain the annealing texture measured in the present study.

In appliance with the orientation growth theory, a formation of the annealing texture is associated with increased mobility of grain boundaries with particular misorientation. Specifically, the $30^{\circ}-40^{\circ}\langle 111\rangle$ boundaries in face-centered cubic metals are often believed to have the relatively high migration mobility [77]. Due to the preferential migration of such boundaries, the annealing texture could be produced by the $30^{\circ}-$ $40^{\circ}\langle 111\rangle$ rotation of the deformation texture. Despite the texture rotation found in the present work was somewhat lower than that predicted by the orientation growth theory, this concept seems to be quite appropriate for explanation of the experimental results.

\subsection{Microstructure-Ductility Relationship}

As shown in Sect. 4.3, the ductility of the prestrained welds was virtually governed by the strain localization in either the stir zone or the base material. Therefore, to establish a relationship between the prestrain path and the weld ductility, it is necessary to compare the final microstructures produced in these areas after $\mathrm{T} 6$ tempering. In this regard, it is important to realize that the prestrain rolling encompassed not only the stir zone but also the base material. Accord- 

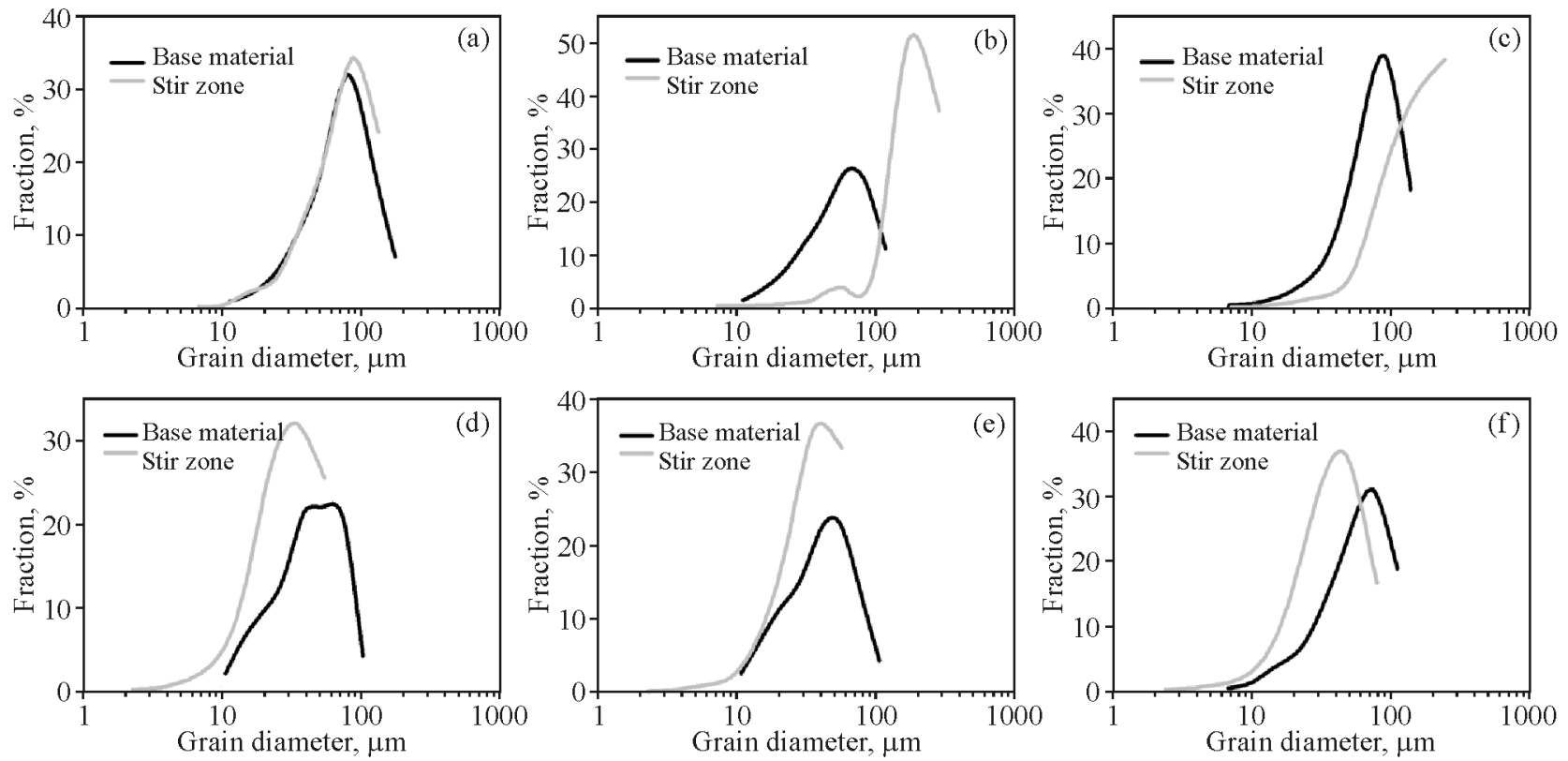

Fig. 18. Comparison of grain size distributions measured in the base material zone and the stir zone in the T6 tempered welds as function of prestrain path: $10 \%$ rolling along welding direction (a), $10 \%$ rolling at $45^{\circ}$ to the welding direction (b), $10 \%$ rolling along transverse direction (c), $20 \%$ rolling along the welding direction (d), $20 \%$ rolling at $45^{\circ}$ to the welding direction (e), and $20 \%$ rolling along the transverse direction (f). See Sect. 4.6 for details.

ingly, the latter region should also experience microstructural changes during subsequent heat treatment. To evaluate the microstructure distribution across the tempered welds, grain size distributions were measured in the stir zone and the base material and then compared in Fig. 18.

In the welds, subjected to either 10 pct rolling along the welding direction or $20 \%$ rolling at $45^{\circ}$ to the welding direction, grain size distributions measured in both microstructural areas were found to broadly overlap with each other (Figs. 18a and 18e, respectively). This agreed well with relatively uniform strain distribution (Figs. 13a and 13e) and the highest ductility (Fig. 12) observed in these welds during transverse tensile tests.

In the joints rolled to $10 \%$ of thickness reduction either at $45^{\circ}$ to the welding direction, or along the transverse direction, the stir zone was characterized by coarser grain structure that the base material (Figs. 18b and 18c). As a result, the tensile strain was localized in the former microstructural region (Figs. 13b and 13c), thus resulting in comparatively low elongation-to-failure (Fig. 12).

In contrast, the welds which undergone $20 \%$ rolling along either the welding direction or the transverse direction were characterized by relatively fine-grained stir zone (Figs. 18d and 18f, respectively). Accordingly, the tensile strain in these cases was preferentially concentrated in the base material region (Figs. 13d and 13f). This also resulted in degradation of the weld ductility (Fig. 12).

\subsection{Preliminary Conclusions}

From the results considered in Sect. 4, the following conclusions could be drawn.

The postweld $\mathrm{T} 6$ treatment provided complete recovery of the weld strength but led to the abnormal grain growth in the stir zone.

The prestrain rolling was shown to be a very effective tool for suppression of the abnormal grain growth.

At relatively low rolling reductions $(10 \%)$, the subsequent annealing behavior was found to be very sensitive to the prestrain path. Specifically, the rolling along the welding direction was established to be the most effective for inhibition of the abnormal grain growth. This effect was attributed to the comparatively high Taylor factor as well as low orientation stability of the FSW-induced texture, which enhanced recrystallization kinetics during subsequent heat treatment. However, an increase of the rolling strain to $20 \%$ of thickness reduction eliminated the anisotropy of the annealing behavior. This result was explained in terms of relatively high dislocation density generated during large rolling strain.

Recrystallization of the stir zone material gave rise to $\mathrm{a} \sim 25^{\circ}\langle 111\rangle$ rotation of the $\mathrm{FSW}$-induced texture. 

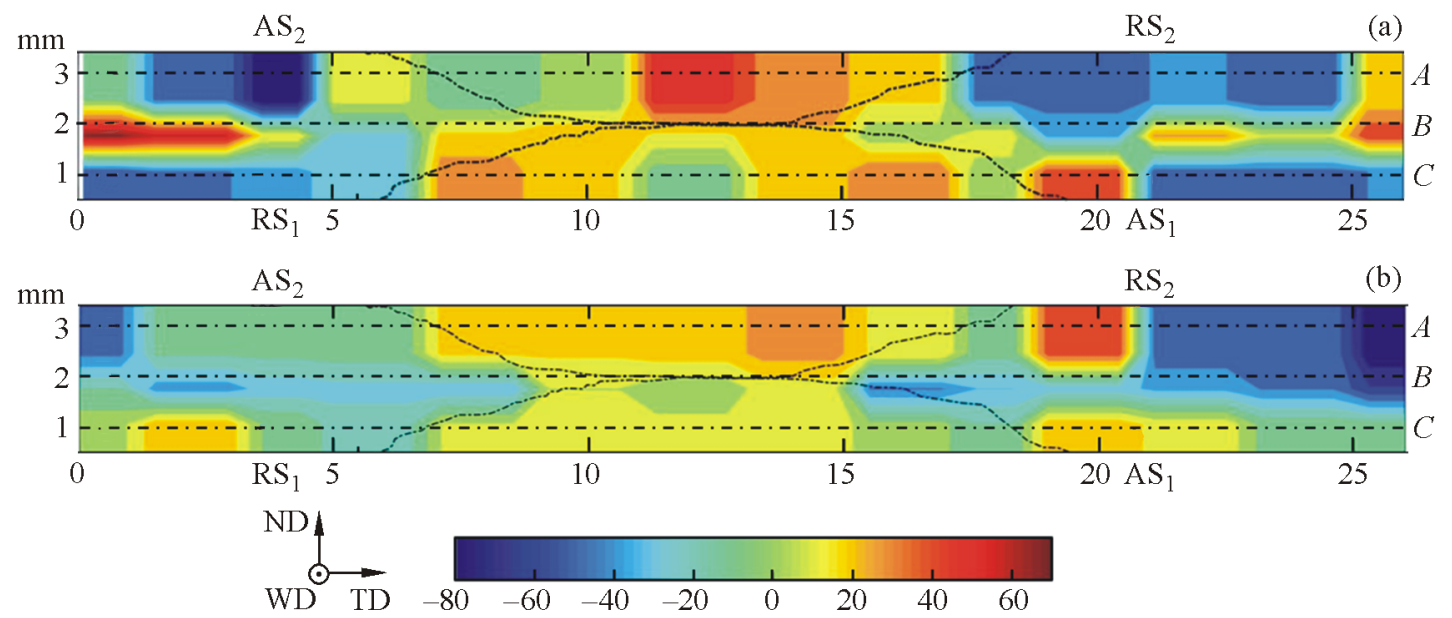

Fig. 19. Residual stress distributions measured on the weld cross section along the transverse $(a)$ and normal direction $(b)$. For clarity, the stir zone borderlines are outlined in both maps (dotted lines). $\mathrm{AS}_{1}\left(\mathrm{AS}_{2}\right)$ and $\mathrm{RS}_{1}\left(\mathrm{RS}_{2}\right)$ denote advancing and retreating sides of the first and second FSW passes, respectively. Note: the horizontal lines $A, B$ and $C$ show the positions at which the residual stress profiles were plotted and shown in Fig. 20 (color online).

This observation was explained in the terms of the orientation growth theory, i.e., attributed to the increased mobility of $\sim 30^{\circ}-40^{\circ}\langle 111\rangle$ boundaries in aluminum.

Tensile behavior of the T6 tempered welds was found to be dictated by the strain localization in relatively coarse-grained regions. The appropriate microstructural control by the prestraining could provide a reasonably uniform microstructure distribution across the weld and thus essentially enhance the weld ductility.

\section{FATIGUE PERFORMANCE OF OPTIMIZED WELDS}

As suggested in Sect. 1.4, optimization of FSW process may inhibit precipitation coarsening and result in relatively high compressive residual stresses. Both these factors should contribute to the enhancement of fatigue performance. To validate this suggestion, fatigue behavior of the optimized welds was examined and then related with the underlying microstruc- ture and residual stresses. The obtained results were summarized below.

\subsection{Residual Stress}

Considering significance of residual stresses in fatigue performance of the welded structures, as discussed in Sect. 1.4, the residual stress distribution was measured in the as-welded condition. Figures 19a and $19 \mathrm{~b}$ show the transverse (along the transverse direction) and through-thickness normal (along the normal direction) residual stress maps, respectively. For clarity, a borderline of the stir zone was also outlined in the maps (dotted lines). It is clear that the magnitude and distributions of both residual stress components substantially vary with position in the weld. To provide an additional insight into this variation, the profiles of the residual stress were measured along three lines across the welds (labelled as $A, B$, and $C$ in Fig. 19) and shown in Fig. 20. These profiles illustrated the stress distribution in the center of the stir

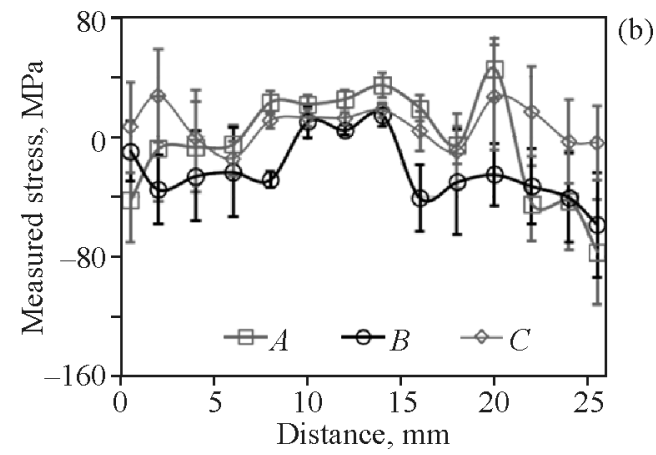

Fig. 20. Profiles of the residual stress measured along the lines shown in Fig. 19 for transverse (a) and normal directions (b). 

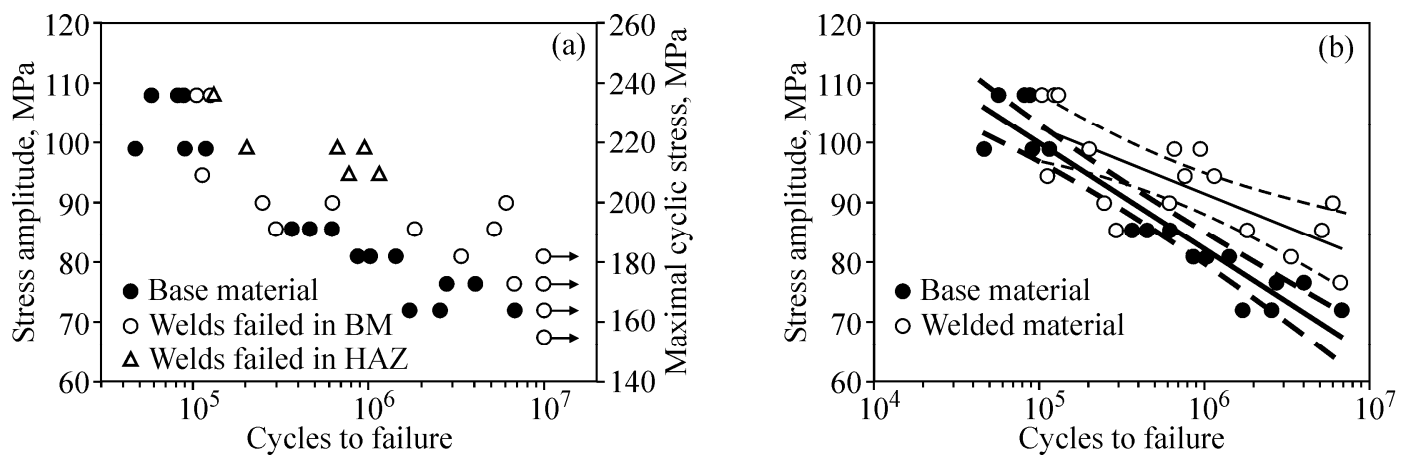

Fig. 21. Fatigue lifetime versus applied stress for the base- and welded materials: entire data set (a), the data used for statistical analysis (b). The arrows represent run-out tests (a); solid lines represent median curves whereas dotted lines show $95 \%$ confidence bands (b). See Sect. 5.2 for details.

zone produced during the second weld pass (line $A$ ), that in the first weld pass (line $C$ ) and also in the overlapping region of both weld passes (line $B$ ).

In all cases, the uncertainties associated with the residual stress measurements were less than $\pm 35 \mathrm{MPa}$ (Fig. 20). Remarkably, the experimental scattering within the stir zone was considerably lower than that measured in the heat-affected zone and/or the base material (Fig. 20). This was presumably due to a substantially finer grain size in the former microstructural region and thus the respectively higher sampling statistics.

The residual stress distributions were found to be fairly heterogeneous (Figs. 19 and 20). This perhaps additionally emphasizes a complex character of structural response to friction-stir welding. However, despite the complexity of the measured distributions, several important observations could be made.

Specifically, the residual stresses were rather tensile in character within the stir zone but compressive in the base material region (Fig. 19). Considering a localized character of material heating during frictionstir welding (and the concomitant thermal expansion of the heated material), this result seems to be quite expectable. The highest tensile stress in the stir zone was measured to be around $+50 \mathrm{MPa}$, whereas the largest compressive stress in the base material was $-80 \mathrm{MPa}$ (Fig. 20a).

It is also worth noting that the upper half of the stir zone exhibited a higher level of the residual stresses than its lower section (Fig. 19). This observation could be attributable to the double-side character of friction-stir welding employed in the present work. That is, the residual stress in the bottom half of the stir zone generated during the first friction-stir welding pass were partially relieved by a thermal effect of the second welding pass.

\subsection{Fatigue Performance}

The effect of cyclic loading on fatigue life of the base and welded materials is shown in Fig. 21a. The statistical details of the test are summarized in Table 4. Despite the fatigue tests were characterized by essential experimental scattering, several important observations were made.

As expected, the fatigue lifetime in both studied material conditions gradually reduced with stress (Fig. 21a). Also quite expectedly, both fatigue diagrams demonstrated no clear saturation (Fig. 21a). Accordingly, no clear fatigue limit could be defined. In this work, therefore, the fatigue limit strength of $10^{7}$ cycles was accepted as a measure of the highcycle fatigue performance.

In appliance with ASTM E 1823-96 standard, the fatigue limit strength is defined as the maximal stress amplitude for which at least $50 \%$ of the tested specimens survived a predetermined number of cycles. If so, the fatigue limit strength for the base material should be $67.5 \mathrm{MPa}$, whereas that for the welded material should be $76.5 \mathrm{MPa}$ (Table 4). In other words, the friction-stir welds exhibited superior fatigue strength as compared to the base material.

To verify this surprising result, the fatigue data were statistically analyzed in accordance with recommendations of ASTM E 739-91 standard. To this end, the run-out tests as well as all suspicious results were excluded from consideration ${ }^{5}$ and the remaining data were linearized as shown in Fig. 21b. It is clear from the figure that the fatigue strength of the welded material at relatively low stress amplitudes had indeed exceeded that of the base material. At relatively high cyclic stresses, however, the measured data points for

\footnotetext{
5 The data excluded from consideration consisted of 13 runout tests $(2$ base material specimens and 11 welded specimens) and 1 suspicious result (welded material).
} 
Table 4. Details of fatigue tests

\begin{tabular}{|c|c|c|c|c|c|}
\hline \multirow{2}{*}{$\begin{array}{l}\text { Amplitude } \\
\text { stress, MPa }\end{array}$} & \multicolumn{2}{|c|}{$\begin{array}{c}\text { Maximal cyclic stress } \\
\text { (in fraction of yield strength } \sigma_{y} \text { ) }\end{array}$} & \multicolumn{2}{|c|}{ Cycles to failure } & \multirow{2}{*}{$\begin{array}{l}\text { Weld failure } \\
\text { location }\end{array}$} \\
\hline & Base material & Welds & Base material & Welds & \\
\hline 67.5 & $0.47 \sigma_{\mathrm{y}}$ & $0.55 \sigma_{\mathrm{y}}$ & Run-out tests & & - \\
\hline \multirow{3}{*}{72} & \multirow{3}{*}{$0.50 \sigma_{\mathrm{y}}$} & \multirow{3}{*}{$0.58 \sigma_{\mathrm{y}}$} & $1,704,748$ & \multirow{3}{*}{$\begin{array}{l}\text { Three run-out } \\
\text { tests }\end{array}$} & \multirow{3}{*}{-} \\
\hline & & & $2,538,856$ & & \\
\hline & & & $6,764,240$ & & \\
\hline \multirow{2}{*}{76.5} & \multirow{2}{*}{$0.54 \sigma_{\mathrm{y}}$} & \multirow{2}{*}{$0.62 \sigma_{\mathrm{y}}$} & $2,763,392$ & $6,717,387$ & $\begin{array}{c}\text { Base } \\
\text { material }\end{array}$ \\
\hline & & & $4,020,179$ & $\begin{array}{l}\text { Two run-out } \\
\text { tests }\end{array}$ & - \\
\hline \multirow{3}{*}{81} & \multirow{3}{*}{$0.57 \sigma_{\mathrm{y}}$} & \multirow{3}{*}{$0.65 \sigma_{\mathrm{y}}$} & 861,513 & $3,360,543$ & $\begin{array}{c}\text { Base } \\
\text { material }\end{array}$ \\
\hline & & & $1,006,680$ & \multirow{2}{*}{$\begin{array}{l}\text { One run-out } \\
\text { test }\end{array}$} & \multirow{2}{*}{-} \\
\hline & & & $1,417,184$ & & \\
\hline \multirow{3}{*}{85.5} & \multirow{3}{*}{$0.60 \sigma_{\mathrm{y}}$} & \multirow{3}{*}{$0.69 \sigma_{\mathrm{y}}$} & 364,845 & 292,961 & \multirow{3}{*}{$\begin{array}{c}\text { Base } \\
\text { material }\end{array}$} \\
\hline & & & 452,393 & $1,829,003$ & \\
\hline & & & 620,615 & $5,183,806$ & \\
\hline \multirow{3}{*}{90} & \multirow{3}{*}{-} & \multirow{3}{*}{$0.73 \sigma_{\mathrm{y}}$} & \multirow{3}{*}{-} & 248,991 & \multirow{3}{*}{$\begin{array}{l}\text { Base } \\
\text { material }\end{array}$} \\
\hline & & & & 619,010 & \\
\hline & & & & $6,029,954$ & \\
\hline \multirow{3}{*}{94.5} & \multirow{3}{*}{-} & \multirow{3}{*}{$0.76 \sigma_{\mathrm{y}}$} & \multirow{3}{*}{-} & 112,994 & $\begin{array}{c}\text { Base } \\
\text { material }\end{array}$ \\
\hline & & & & 771,268 & \multirow{2}{*}{$\begin{array}{l}\text { Heat-affected } \\
\text { zone }\end{array}$} \\
\hline & & & & $1,145,951$ & \\
\hline \multirow{3}{*}{99} & \multirow{3}{*}{$0.70 \sigma_{\mathrm{y}}$} & & 46,472 & 202,805 & \\
\hline & & $0.80 \sigma_{\mathrm{y}}$ & 90,369 & 661,812 & $\begin{array}{c}\text { Heat-affected } \\
\text { zone }\end{array}$ \\
\hline & & & 115,993 & 943,967 & \\
\hline & & & 57,046 & 125,552 & $\begin{array}{c}\text { Base } \\
\text { material }\end{array}$ \\
\hline 108 & $0.76 \sigma_{\mathrm{y}}$ & $0.87 \sigma_{\mathrm{y}}$ & 83,048 & 104,777 & Heat-affected \\
\hline & & & 87,718 & 129,689 & zone \\
\hline
\end{tabular}

both studied material conditions tended to overlap thus indicating a comparable strength level.

Another important issue was the failure location of the welded specimens. At relatively low amplitude stresses $(<94.5 \mathrm{MPa})$, the welds failed exclusively in the base material section (Table 4), despite this region exhibited a relatively high strength under static loading condition (Figs. 3 and 7a). At higher amplitude stress, however, the fatigue failure often occurred in the heat-affected zone (Table 4), i.e., the softest microstructural region of the optimized welds.

\subsection{Fracture Analysis}

To get additional insight into the fatigue performance, fracture surface of the fatigues specimens was examined. Three characteristic cases were considered for this purpose, viz. base material, the welds fatigued at relatively low stresses and failed in the base material region, and the welds fatigued at relatively high stress and failed in the heat-affected zone.

Typical appearance of the specimens representing three above groups is shown in Fig. 22. The magnified images of the failure locations are given in the top 
(a)

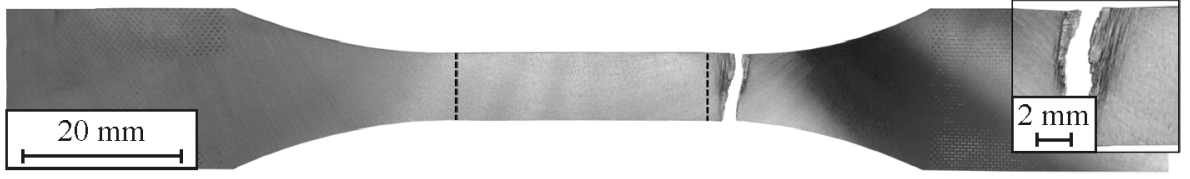

(b)

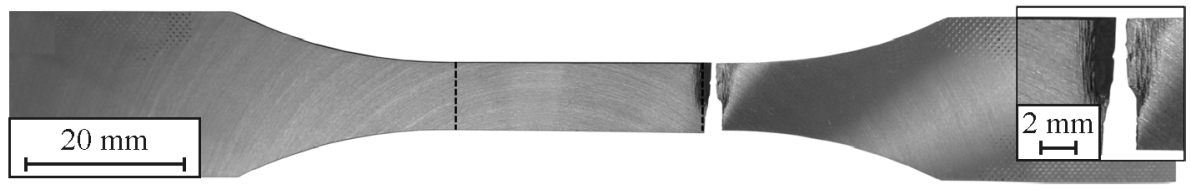

(c)

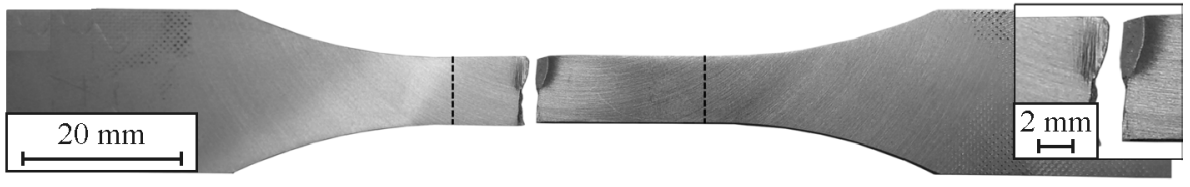

Fig. 22. Typical appearances of the specimens failed during fatigue tests: base material (a), the weld fatigued at a relatively low stress magnitude and failed in the base material zone (b), and the weld fatigued at a relatively high stress magnitude and failed in the heat-affected zone (c). The magnified images of fracture surfaces are shown in the top right corners of the figures. The dotted lines show the gauge length of each specimen. Amplitude stress of 72 (a), 90 (b) and $99 \mathrm{MPa}$ (c).

right corners of the appropriate micrographs. In all cases, the fracture profile was relatively complex being comprised by two more or less distinct constituents. One of the segments was relatively flat thus indicating a brittle mechanism of fracture. The second one was characterized by a developed surface relief thus probably evidencing a ductile failure (high magnification inserts in Fig. 22) ${ }^{6}$.

The direct observations of fracture surfaces have confirmed the relatively complex character of the failure process (Figs. 23a, 24a and 25a). In all cases, three characteristics regions were observed, which represented three typical stages of fatigue failure: crack initiation (stage I), crack propagation (stage II), and catastrophic fracture (stage III) [131, 132].

Typically, the fatigue crack was found to initiate at the lateral surface of the specimens (Figs. 23a, 23b and 24a). This was likely due to the relatively high roughness of these surfaces, as noted in Sect. 2.6. In some welded surfaces, however, the crack nucleation was also observed at the upper weld surface (Figs. 25a, 25b). The fracture surface at stage I was highly faceted (Figs. 23b and 24b) thus perhaps indicating that the crack nucleation occurred by a slipplane cracking.

In stage II, the fracture surface was dominated by fatigue striations (Figs. 23c, 24c and 25c), which are

\footnotetext{
6 It should be also noted that some fraction of the tested specimens ( 2 out 17 in the base material and 3 out 17 in the welded material) failed either close to the borderline of the gauge section (Fig. 22b) or slightly outside it (Fig. 22a). This observation was thought to be attributable to a smooth transition between the gauge and grip sections of the fatigue specimens.
}

conventionally attributed to a discontinuous character of the crack propagation [132]. In some cases, small secondary cracks were also observed (Fig. 23c). Remarkably, the striations were typically arranged into larger-scale banded structure, thus exhibiting a relatively complex nature of failure. Sometimes, contours of original grains may also be seen (Fig. 23b). This may evidence the preferential crack propagation along original grain boundaries which led to the material decohesion $[131,132]$.

The fracture surfaces at stages I and II were relatively smooth, thus indicating a brittle character of failure (Figs. 23b, 23c, 24b, 24c, and 25b, 25c). In contrast, stage III exhibited a dimpled appearance (Figs. 23d, 24d, and 25d), thereby evidencing a ductile fracture mechanism governed by the nucleation and coalescence of voids.

From a broad perspective, the fracture analysis given above revealed no principal difference between the studied specimens. This probably indicated a nearly-similar character of the crack propagation in all studied cases. In this context, of interest was the observation that the global fracture surface was dominated by stage III (Figs. 23a, 24a, and 25a), i.e. the crack propagation resistance was relatively low. This suggests that fatigue performance of the welded material was probably dictated by the crack initiation process.

\subsection{Broad Aspects of Fatigue Behavior}

As noted in Sect. 1.4, it is believed that fatigue behavior of friction-stir welds is governed by the following primary factors, viz. geometrical characteristics of FSW process including tool marks and the "kissing 

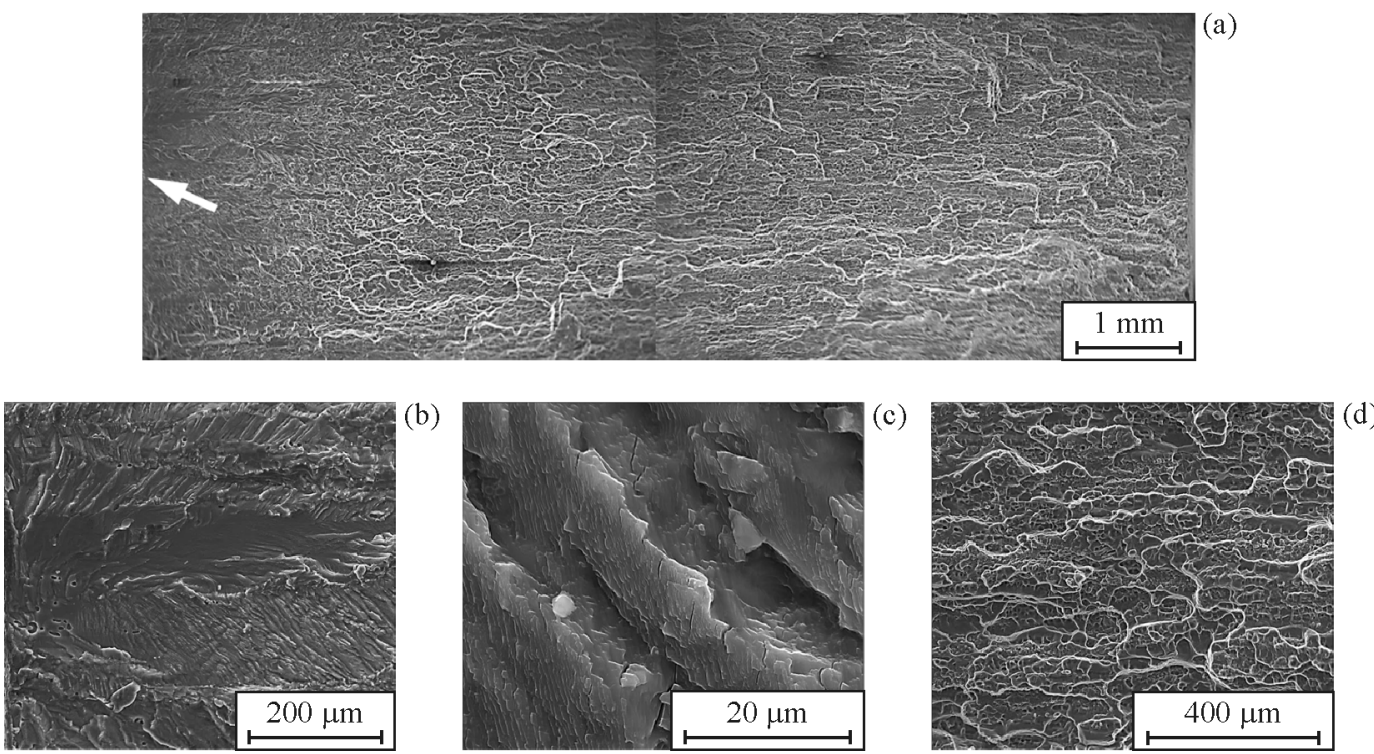

Fig. 23. SEM micrographs showing typical fracture surfaces of the base material: low-magnification overview (a) and characteristic areas given at higher magnifications in (b) through to (d). In (a), the arrow is pointing at the likely crack initiation site. See Sect. 5.3 for details. Note: The sample was fatigued at amplitude stress magnitude of $72 \mathrm{MPa}$.

bond" defect, weld flaws, microstructure, and residual stresses $[1,2]$. Since the welds examined in the present work contained no sample-scale defects (Fig. 2c) and were carefully polished to remove the tool marks, only the microstructure and residual stresses were of critical importance.

As deduced in Sect. 5.3, fatigue life of the examined welds was likely dictated by the crack initiation stage. It is widely accepted that the fatigue cracks typically nucleate from the slip bands [132]. Hence, a suppression of the slip banding due to a grain refine- ment is frequently believed to improve the crack initiation resistance [133-135]. It is likely therefore that the excellent fatigue resistance of the stir zone material observed in the present work was related (partially, at least) to the pronounced grain refinement occurring in this microstructural region during friction-stir welding (Fig. 5c).

On the other hand, the heat-affected zone experienced no grain refinement during friction-stir welding. Therefore, considering a notable material softening in this microstructural region (Fig. 3) due to the particle
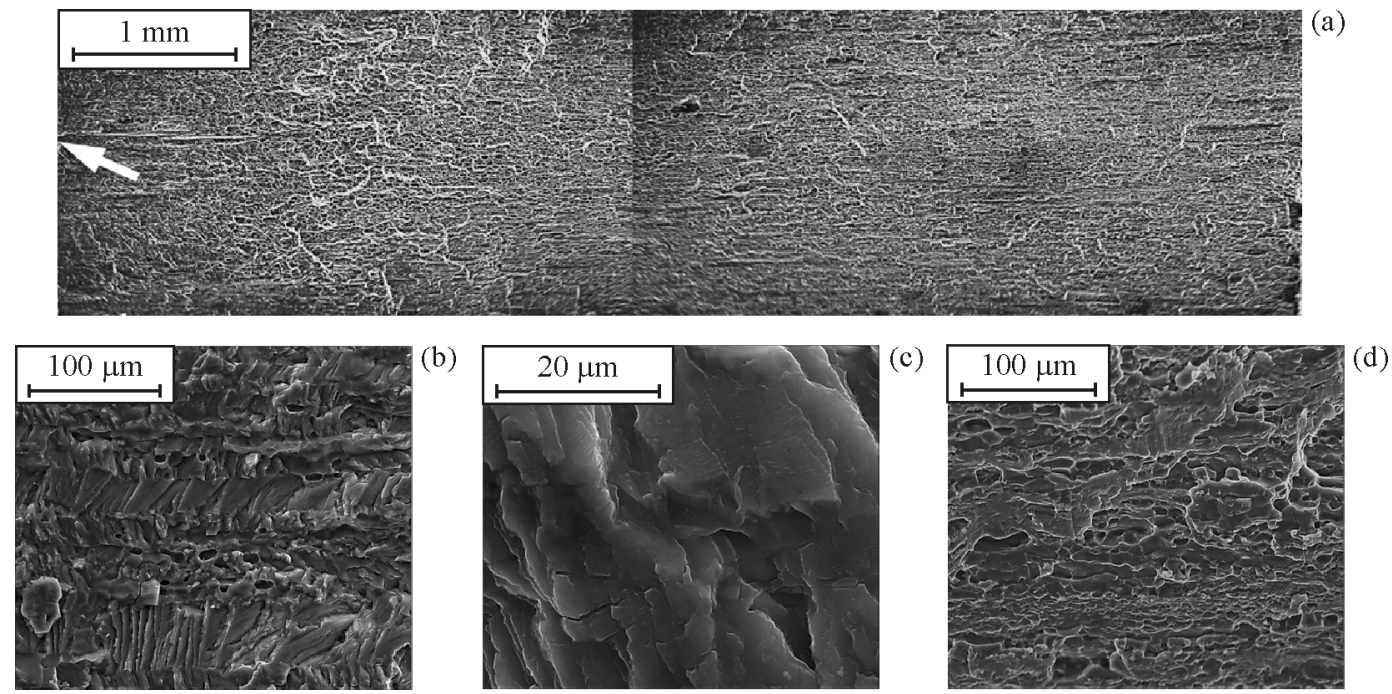

Fig. 24. SEM micrographs showing typical fracture surface of the welds, fatigued at a relatively low stress where the failure was occurred at the base-material zone: low-magnification overview (a) and characteristic areas given at higher magnifications in (b) through to (d). In (a), the arrow is pointing at the likely crack initiation site. See Sect. 5.3 for details. Note: The sample was fatigued at the amplitude stress magnitude of $76.5 \mathrm{MPa}$. 

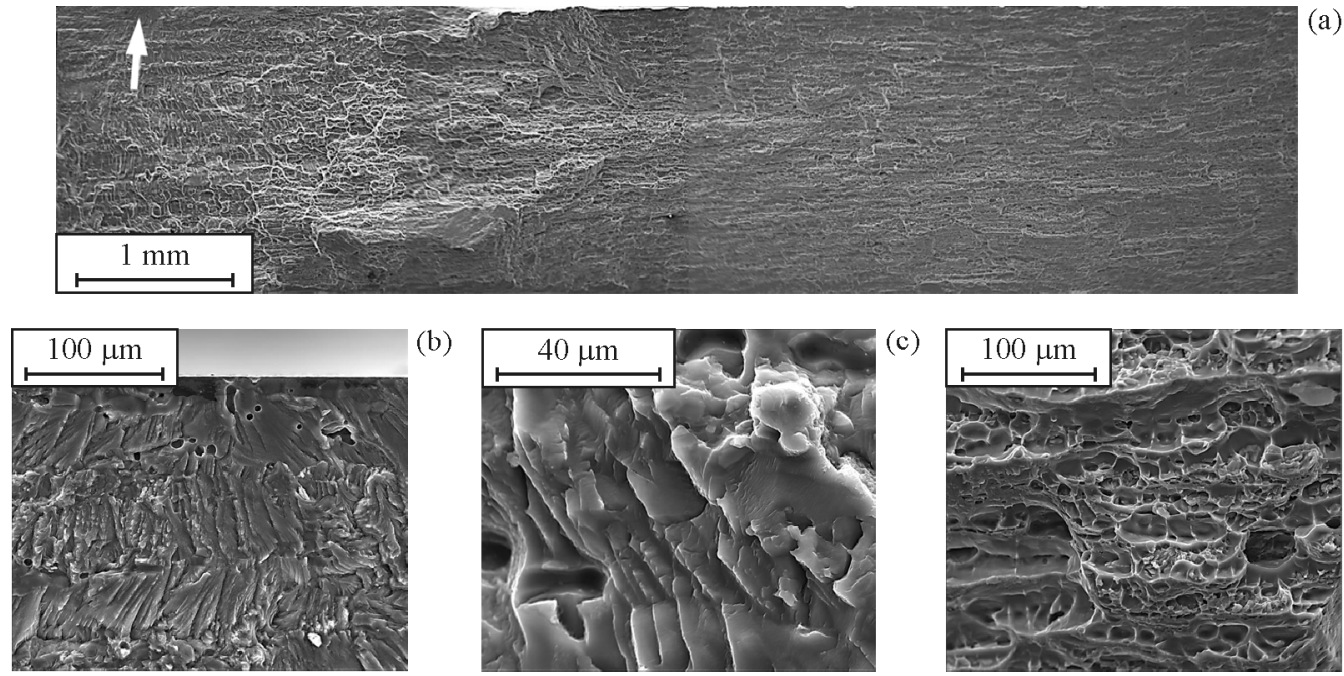

(b)
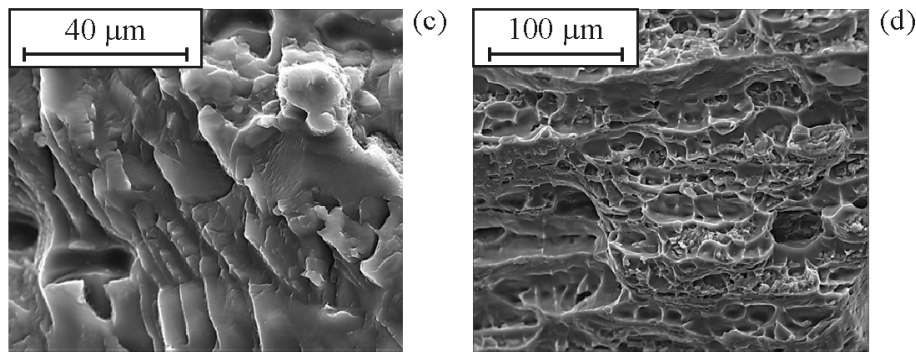

Fig. 25. SEM micrographs showing fracture surface of the welds fatigued at a relatively high stress where the failure was occurred at the heat-affected zone: low-magnification overview (a) and characteristic areas given at higher magnifications in (b) through to (d). In (a), the arrow is pointing at the likely crack initiation site. See Sect. 5.3 for details. Note: The sample was fatigued at the amplitude stress magnitude of $94.5 \mathrm{MPa}$.

coarsening (Fig. 4e) as well as the concomitant reduction of mechanical properties under static loading (Fig. 7a), it was somewhat surprising that the fatigued specimens often failed in the base material region (Table 4). To comprehend this result, fatigue behavior under low and high cyclic stresses is discussed in the following two sections.

\subsection{Low Cyclic Stresses}

At relatively low magnitude of cyclic stress $(<210 \mathrm{MPa})$, a crack was found to nucleate primarily in the base material zone; however, the welded specimens exhibited generally longer fatigue life than the base material specimens (Fig. 21a, Table 4).

These apparently contradictory results could be explained by considering two factors, including stochastic nature of nucleation of the fatigue crack, and significant compressive residual stresses in the base material region of the welded specimens (Figs. 19a and 20a). Indeed, the maximal fatigue stress in this case did not exceed $\sim 60-70 \%$ of the static yield strength (Table 4) and thus an initiation of the fatigue crack was probably governed by the purely stochastic factors. Since the base material section comprised $\sim 60 \%$ of the gauge length of fatigue specimens, the statistical probability of the crack nucleation in this microstructural region was greatest. It was also highly likely that the initiation of the fatigue crack there was additionally promoted by the coarse grained microstructure of the base material zone (Fig. 1a).

On the other hand, due to the relatively high residual compressive stresses generated during friction- stir welding (Figs. 19 and 20), the base material zone of the welded specimens should exhibit a higher fatigue resistance than the original material.

\subsection{High Cyclic Stresses}

At relatively high magnitude of cyclic stress $(\geq 210 \mathrm{MPa})$, the welds often failed in the heat-affected zone (Fig. 21a, Table 4), i.e., the softest microstructural region. Nevertheless, the welded specimens showed the fatigue strength comparable to that of the base material specimens (Fig. 21).

To comprehend the fatigue behavior in this case, it is important to realize that the maximal cyclic stresses reached $\sim 90 \%$ of the static yield strength (Table 4 ). Considering a relatively high residual tensile stresses in the heat-affected zone (Figs. 19a and 20a), it is likely that the total tensile stress in this area exceeded the yield strength level and thus the material experienced a plastic strain prior nucleation of the fatigue crack.

To evaluate this idea, microhardness profiles were measured across the failed welds and compared with these of the nonfatigued ones, as exemplified in Fig. 26. The measurable material strengthening revealed in the weld zone after the fatigue test appears to be indicative of a strain hardening effect. If so, the fatigue crack has indeed originated from a proceeding plastic strain. This perhaps explains the observed fai lure of the welds in the softest microstructural region, i.e., the heat-affected zone. On the other hand, due to a relatively small difference in strength between this microstructural area and the base material $(\sim 10 \%$, as 


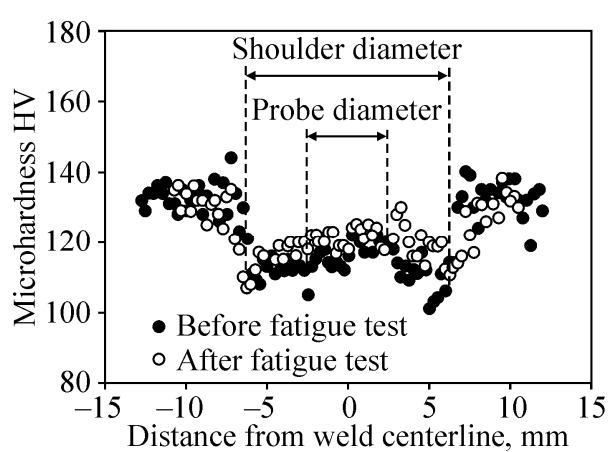

Fig. 26. Effect of high-stress fatigue on microhardness profile measured across the welded specimen. See Sect. 5.6 for details. Note: The experimental data were taken from the weld specimen after fatigue test at the amplitude stress magnitude of $108 \mathrm{MPa}$.

follows from Fig. 26), as well as a substantial influence of the stochastic factor on the cyclic behavior, the fatigue strength of the welded specimens was comparable to that of the base material and a significant portion of the welds failed in the parent material zone.

With approaching of the magnitude of the fatigue stress to the static yield strength, the role of the plastic deformation on the fatigue behavior is expected to increase. This is consistent with the fatigue diagrams in Fig. $21 \mathrm{~b}$, which predict inferior fatigue strength of the welded material in the low-cycle fatigue range.

\subsection{Preliminary Conclusions}

From the results considered in Sect. 5, the following conclusions could be drawn.

The optimized welds exhibited excellent fatigue performance that was comparable (and even superior) to that of the base material.

At relatively low fatigue stress $(<210 \mathrm{MPa})$, the welds typically failed in the base material region. This effect was attributed to a stochastic nature of the fatigue crack nucleation. Remarkably, the welded specimens showed longer fatigue life than the base material specimens. This result was explained in the terms of relatively-high compressive residual stress (up to $\sim 80 \mathrm{MPa}$ ) generated in the base material region during friction-stir welding.

At relatively high fatigue stress $(\geq 210 \mathrm{MPa})$, fracture often occurred in the softest microstructural region, i.e., the heat-affected zone. This observation was also associated with substantial tensile residual stress (up to $\sim 70 \mathrm{MPa}$ ) produced in this area during frictionstir welding. It was suggested that a sum of the applied fatigue stress and the residual stress in this zone exceeded the yield point and therefore the material expe- rienced a plastic strain prior to the nucleation of the fatigue crack. On the other hand, due to the subtle character of the softened effect in the heat-affected zone $(\sim 10 \%)$ and the stochastic nature of the fatigue cracking, significant portion of the welds failed in the base material zone. Accordingly, the fatigue strength of the welded specimens was comparable to that of the parent material.

In the heat-affected zone as well as the base material, the crack initiation was facilitated by relatively coarse-grained microstructure.

Despite the significant tensile residual stress revealed in the stir zone (up to $\sim 50 \mathrm{MPa}$ ), as well as a relatively low static strength of the stir zone material, none of the welds failed in this microstructural region. This effect was attributed to significant grain refinement occurred in this area during friction-stir welding.

\section{SUMMARY}

Due to the relatively high-temperature character of FSW process, it typically involves complex precipitation phenomena in heat-treatable aluminum alloys. These typically includes particle coarsening in the heat-affected zone and particle dissolution in the stir zone, both leading to essential degradation of mechanical properties of such materials. The present work aimed to overcome these problems in order to provide a nearly $100 \%$ joint efficiency in friction-stir welded heat-treatable aluminum alloys. To this end, 6061-T6 aluminum alloy was used as a program material and two strategies were employed for this purpose.

The first strategy involved optimization of FSW variables in order to provide a combination of a relatively high welding temperature and the shortest possible thermal cycle during friction-stir welding. In this case, the precipitation coarsening occurring during friction-stir welding could be inhibited and thus the material properties could be recovered during the standard postweld aging process. Moreover, the relatively high residual stress associated with such thermal cycle as well as drastic grain refinement induced by the friction-stir welding should improve fatigue performance of the welds. Detailed microstructural observations as well as thorough examinations of mechanical properties have confirmed a reliability of the proposed approach. Specifically, a joint efficiency of $97 \%$ for the yield strength was achieved, whereas the fatigue behavior of the welds was found to be even superior to that of the base material.

The second approach was based on the application of the standard postweld T6 tempering involving a so- 
lutionizing treatment followed by the artificial aging. This procedure should provide a relatively uniform precipitation of strengthening dispersoids across the welded material and thus complete recovering of material properties. It was found, however, that the solutionizing annealing led to the abnormal grain growth in the stir zone which had a detrimental effect on the weld ductility.

To inhibit this undesirable phenomenon, the prestrain rolling of the welds was applied prior to the T6 tempering. It was shown that the prestraining was effective for suppression of the abnormal grain growth due to the activation of a competing recrystallization process. At relatively low prestrain rolling, the subsequent annealing behavior was found to be considerably influenced by the prestrain path. This effect was attributed to the sensitivity of Taylor factor as well as to the orientation stability of the as-welded microstructure to the rolling direction. At relatively high pre-rolling reductions, however, the anisotropy of the annealing behavior was eliminated presumably due the relatively high dislocation density generated in the material irrespective on the applied rolling path.

It was also established that recrystallization of the stir zone material gave rise to a $\sim 25^{\circ}\langle 111\rangle$ rotation of the FSW-induced texture. This observation was explained in the terms of the orientation growth theory, i.e., attributed to the increased mobility of $\sim 30^{\circ}-$ $40^{\circ}\langle 111\rangle$ boundaries in aluminum.

\section{FUNDING}

This work was partially supported by the Russian Science Foundation under the grant No. 19-49-02001. The authors also would like to thank the personnel of the Joint Research Center "Technology and Materials" at Belgorod State National Research University for assistance with experimental work.

\section{REFERENCES}

1. Mishra, R.S. and Ma, Z.Y., Friction Stir Welding and Processing, Mater. Sci. Eng. R, 2005, vol. 50, pp. 1-78. doi 10.1016/j.mser.2005.07.001

2. Threadgill, P.L., Leonard, A.J., Shercliff, H.R., and Withers, P.J., Friction Stir Welding of Aluminum Alloys, Int. Mater. Rev., 2009, vol. 54, pp. 49-93. doi 10.1179/1743 28009X411136

3. Su, J.-Q., Nelson, T.W., Mishra, R., and Mahoney, M., Microstructural Investigation of Friction Stir Welded 7050-T651 Aluminum, Acta Mater., 2003, vol. 51, pp. 713-729. doi 10. 1016/s1359-6454(02)00449-4

4. Jata, K.V., Sankaran, K.K., and Ruschau, J.J., Friction-Stir Welding Effects on Microstructure and Fatigue of Aluminum
Alloy 7050-T7451, Metall. Mater. Trans. A, 2000, vol. 31, pp. 2181-2192. doi 10.1007/s11661-000-0136-9

5. Dumont, M., Steuwer, A., Deschamps, A., Peel, M., and Withers, P.J., Microstructure Mapping in Friction Stir Welds of 7449 Aluminum Alloy Using SAXS, Acta Mater., 2006, vol. 54, pp. 4793-4801. doi 10.1016/j.actamat.2006.06.015

6. Sato, Y.S., Kokawa, H., Enomoto, M., and Jogan, S., Microstructural Evolution of 6063 Aluminum during Friction-Stir Welding, Metall. Mater. Trans. A, 1999, vol. 30, pp. 2429 2437. doi 10.1007/s11661-999-0251-1

7. Heinz, B. and Skrotzki, B., Characterization of a FrictionStir-Welded Aluminum Alloy 6013, Metall. Mater. Trans. B, 2002, vol. 33, pp. 489-498. doi 10.1007/s11663-002-0059-5

8. Lee, W.B., Yeon, Y.M., and Jung, S.B., Evaluation of the Microstructure and Mechanical Properties of Friction Stir Welded 6006 Aluminum Alloy, Mater. Sci. Technol., 2003, vol. 19, pp. 1513-1518. doi 10.1179/026708303225008068

9. Lee, W.-B., Yeon, Y.-M., and Jung, S.-B., Mechanical Properties Related to Microstructural Variation of 6061 Al Alloy Joints by Friction Stir Welding, Mater. Trans., 2004, vol. 45, pp. 1700-1705. doi 10.2320/matertrans. 45.1700

10. Cabibbo, M., McQueen, H.J., Evangelista, E., Spigarelli, S., Paola, M.D., and Falchero, A., Microstructure and Mechanical Property Studies of AA6056 Friction Stir Welds, Mater. Sci. Eng. A, 2007, vol. 460-461, pp. 86-94. doi 10.1016/ j.msea.2007.01.022

11. Woo, W., Choo, H., Brown, D.W., and Feng, Z., Influence of the Tool Pin and Shoulder on Microstructure and Natural Aging Kinetics in a Friction-Stir-Processed 6061-T6 Aluminum Alloy, Metall. Mater. Trans. A, 2007, vol. 38, pp. 69-76. doi 10.1007/s11661-006-9034-0

12. Gallais, C., Denquin, A., Brechet, Y., and Lapasset, G., Precipitation Microstructures in an AA6056 Aluminum Alloy after Friction Stir Welding: Characterization and Modelling, Mater. Sci. Eng. A, 2008, vol. 496, pp. 77-89. doi 10.1016/ j.msea.2008.06.033

13. Sumar, A., Brechet, Y., de Meester, B., Denquin, A., and Pardoen, T., Microstructure, Local and Global Mechanical Properties of Friction Stir Welds in Aluminum Alloy 6005A-T6, Mater. Sci. Eng., 2008, vol. 486, pp. 85-95. doi 10.1016/ j.msea.2007.08.041

14. Dong, P., Li, H., Sun, D., Gong, W., and Liu, J., Effect of Welding Speed on the Microstructure and Hardness in Friction Stir Welding Joints of 6005A-T6 Aluminum Alloy, Mater. Design, 2013, vol. 45, pp. 524-531. doi 10.1016/ j.matdes.2012.09.040

15. Dong, P., Sun, D., and Li, H., Natural Aging Behavior of Friction Stir Welded 6005A-T6 Aluminum Alloy, Mater. Sci. Eng. A, 2013, vol. 576, pp. 29-35. doi 10.1016/j.msea. 2013.03.077

16. Paglia, C.S. and Buchheit, R.G., Microstructure, Microchemistry and Environmental Cracking Susceptibility of Friction Stir Welded 2219-T87, Mater. Sci. Eng. A, 2006, vol. 429, pp. 107-114. doi 10.1016/j.msea.2006.05.036

17. Srinivasan, P.B., Arora, K.S., Dietzel, W., Pandey, S., and Schaper, M.K., Characterization of Microstructure, Mechanical Properties and Corrosion Behavior of an AA2219 Friction Stir Weldment, J. Al. Comp., 2010, vol. 492, pp. 631-637. doi 10.1016/j.jallcom.2009.11.198

18. Arora, K.S., Pandey, S., Schaper, M., and Kumar, R., Microstructure Evolution during Friction Stir Welding of Aluminum Alloy AA2219, J. Mater. Sci. Technol., 2010, vol. 26, pp. 747-753. doi 10.1016/S1005-0302(10)60118-1 
19. Genevois, C., Deschamps, A., Denquin, A., and DoisneauCottignies, B., Quantitative Investigation of Precipitation and Mechanical Behavior for AA2024 Friction Stir Welds, Acta Mater., 2005, vol. 53, pp. 2447-2458. doi 10.1016/j.actamat. 2005.02.007

20. Jones, M.J., Heurtier, P., Desrayaud, C., Montheillet, F., Allehaux, D., and Driver, J.H., Correlation between Microstructure and Microhardness in a Friction Stir Welded 2024 Aluminum Alloy, Scripta Mater., 2005, vol. 52, pp. 693-697. doi 10.1016/j.scriptamat.2004.12.027

21. Fonda, R.W. and Bingert, J.F., Microstructural Evolution in the Heat-Affected Zone of a Friction Stir Weld, Metall. Mater. Trans. A, 2004, vol. 35, pp. 1487-1499. doi 10.1007/ s11661-004-0257-7

22. Fonda, R.W. and Bingert, J.F., Precipitation and Grain Refinement in a 2195 Al Friction Stir Weld, Metall. Mater. Tran., 2006, vol. 37, pp. 3593-3604. doi 10.1007/s11661006-1054-2

23. Sullivan, A. and Robson, J.D., Microstructural Properties of Friction Stir Welded and Post-Weld Heat-Treated 7449 Aluminum Alloy Thick Plate, Mater. Sci. Eng. A, 2008, vol. 478, pp. 351360. doi 10.1016/j.msea.2007.06.025

24. Steuwer, A., Dumont, M., Altenkirch, J., Birosca, S., Deschamps, A., Prangnell, P.B., and Withers, P.J., A Combined Approach to Microstructure Mapping of an Al-Li AA2199 Friction Stir Weld, Acta Mater., 2011, vol. 59, pp. 3002 3011. doi 10.1016/j.actamat.2011.01.040

25. Litynska, L., Braun, R., Staniek, G., Dalle Donne, C., and Dutkiewicz, J., TEM Study of the Microstructure Evolution in a Friction Stir-Welded AlCuMgAg Alloy, Mater. Chem. Phys., 2003, vol. 81, pp. 293-295. doi 10.1016/S02540584(02)00605-3

26. Shukla, A.K. and Baeslack, W.A., Study of Process/Structure/Property Relationships in Friction Stir Welded Thin Sheets Al-Cu-Li Alloy, Sci. Technol. Weld. Join., 2009, vol. 14, pp. 376-387. doi 10.1179/136217109X412409

27. Feng, X., Liu, H., and Lippold, J.C., Microstructure Characterization of the Stir Zone of Submerged Friction Stir Processed Aluminum Alloy 2219, Mater. Character., 2013, vol. 82, pp. 97-102. doi 10.1016/j.matchar.2013.05.010

28. Malopheyev, S., Vysotskiy, I., Kulitskiy, V., Mironov, S., and Kaibyshev, R., Optimization of Processing-Microstructure-Properties Relationship in Friction-Stir Welded 6061-T6 Aluminum Alloy, Mater. Sci. Eng. A, 2016, vol. 662, pp. 136-143. doi 10.1016/j.msea.2016.03.063

29. Cao, C., Zhu, Z., Han, J., and Li, H., Correlation of Microstructure and Mechanical Properties in Friction Stir Welded 2198-T8 Al-Li Alloy, Mater. Sci. Eng. A, 2015, vol. 639, pp. 489-499. doi 10.1016/j.msea.2015.05.038

30. Rao, T.S., Reddy, G.M., and Rao, S.R.K., Microstructure and Mechanical Properties of Friction Stir Welded AA7075-T651 Aluminum Alloy Thick Plates, Trans. Nonfer. Metal. Soc. Chin., 2015, vol. 25, pp. 1770-1778. doi 10.1016/S10036326(15)63782-7

31. Rhodes, C.G., Mahoney, M.W., Bingel, W.H., Spurling, R.A., and Bampton, C.C., Effects of Friction Stir Welding on Microstructure of 7075 Aluminum, Scripta Mater., 1997, vol. 36, pp. 69-75. doi 10.1016/S1359-6462(96)00344-2

32. Feng, A.H., Chen, D.L., and Ma, Z.Y., Microstructure and Cyclic Deformation Behavior of a Friction-Stir-Welded 7075 Al Alloy, Metall. Mater. Trans. A, 2010, vol. 41, pp. 957971. doi 10.1007/s11661-009-0152-3

33. Liu, H.J., Hou, C.J., and Guo, H., Effect of Welding Speed on Microstructure and Mechanical Properties of Self-Reacting
Friction Stir Welded 6061-T6 Aluminum Alloy, Mater. Design, 2013, vol. 50, pp. 872-878. doi 10.1016/j.matdes.2013. 03.105

34. Feng, A.H., Chen, D.L., and Ma, Z.Y., Microstructure and Low-Cycle Fatigue of a Friction-Stir Welded 6061 Aluminum Alloy, Metall. Mater. Trans. A, 2010, vol. 41, pp. 2626-2641. doi 10.1007/s11661-010-0279-2

35. Olea, C.A.W., Roldo, L., dos Santos, J.F., and Strohaecker, T.R., A Substructural Analysis of Friction Stir Welded

Joints in an AA6056 Al-Alloys in T4 and T6 Temper Conditions, Mater. Sci. Eng. A, 2007, vol. 454-455, pp. 52-62. doi 10.1016/j.msea.2006.12.055

36. Surekha, K., Murty, B.S., and Rao, K.P., Microstructural Characterization and Corrosion Behavior of Multipass Friction Stir Processed AA2219 Aluminum Alloy, Surf. Coat. Technol., 2008, vol. 202, pp. 4057-4068. doi 10.1016/ j.surfcoat.2008.02.001

37. Cai, B., Zheng, Z.Q., He, D.Q., Li, S.C., and Li, H.P., Friction Stir Weld of 2060 Al-Cu-Li Alloy: Microstructure and Mechanical Properties, J. All. Comp., 2015, vol. 649, pp. 1927. doi 10.1016/j.jallcom.2015.02.124

38. Giles, T.L., Oh-Ishi, K., Zhilyaev, A.P., Swaminathan, S., Mahoney, M.W., and McNelley, T.R., The Effect of Friction Stir Processing on the Microstructure and Mechanical Properties of an Aluminum Lithium Alloy, Metall. Mater. Trans. A, 2009, vol. 40, pp. 104-115. doi 10.1007/s11661-008-9698-8

39. Qin, H., Zhang, H., and Wu, H., The Evolution of Precipitation and Microstructure in Friction Stir Welded 2195-T8 AlLi Alloy, Mater. Sci. Eng. A, 2015, vol. 626, pp. 322-329. doi 10.1016/j.msea.2014.12.026

40. Hassan, Kh.A.A., Norman, A.F., Price, D.A., and Prangnell, P.B., Stability of Nugget Zone Grain Structures in High Strength Al-Alloy Friction Stir Welds during Solution Treatment, Acta Mater., 2003, vol. 51, pp. 1923-1936. doi 10. 1016/S1359-6454(02)00598-0

41. Attallah, M.M. and Salem, H.G., Friction Stir Welding Parameters: A Tool for Controlling Abnormal Grain Growth during Subsequent Heat Treatment, Mater. Sci. Eng. A, 2005, vol. 391, pp. 51-59. doi 10.1016/j.msea.2004.08.059

42. Charit, I. and Mishra, R.S., Abnormal Grain Growth in Friction Stir Processed Alloys, Scripta Mater., 2008, vol. 58, pp. 367-371. doi 10.1016/j.scriptamat.2007.09.052

43. Ipekoglu, G., Erim, S., and Cam, G., Investigation into the Influence of Post-Weld Heat Treatment on the Friction Stir Welded AA6061 Al Alloy Plates with Different Temper Conditions, Metall. Mater. Trans. A, 2014, vol. 45, pp. 864-877. doi 10.1007/s11661-013-2026-y

44. Jana, S., Mishra, R.S., Baumann, J.A., and Grant, G., Effect of Process Parameters on Abnormal Grain Growth during Friction Stir Processing of a Cast Al Alloy, Mater. Sci. Eng. $A$, 2010, vol. 528, pp. 189-199. doi 10.1016/j.msea.2010. 08.049

45. Chen, K., Gan, W., Okamoto, K., Chung, K., and Wagoner, R.H., The Mechanism of Grain Coarsening in FrictionStir-Welded AA5083 after Heat Treatment, Metall. Mater. Trans. A, 2011, vol. 42, pp. 488-507. doi 10.1007/s11661010-0426-9

46. Sato, Y.S., Watanabe, H., and Kokawa, H., Grain Growth Phenomena in Friction Stir Welded 1100 Al during PostWeld Heat Treatment, Sci. Technol. Weld. Join., 2007, vol. 12, pp. 318-323. doi 10.1179/174329307X197575

47. Chen, Y., Ding, H., Li, J., Cai, Z., Zhao, J., and Yang, W., Influence of Multi-Pass Friction Stir Processing on the Micro- 
structure and Mechanical Properties of Al-5083 Alloy, Mater. Sci. Eng. A, 2016, vol. 650, pp. 281-289. doi 10.1016/j.msea. 2015.10.057

48. Carcia-Bernal, M.A., Mishra, R.S., Verma, R., and Hernandez-Silva, D., Influence of Friction Stir Processing Tool Design on Microstructure and Superplastic Behavior of Al-Mg Alloys, Mater. Sci. Eng. A, 2016, vol. 670, pp. 9-16. doi 10. 1016/j.msea.2016.05.115

49. Mironov, S., Masaki, K., Sato, Y.S., and Kokawa, H., Relationship between Material Flow and Abnormal Grain Growth in Friction-Stir Welds, Scripta. Mater., 2012, vol. 67, pp. 983-986. doi 10.1016/j.scriptamat.2012.09.002

50. Mironov, S., Masaki, K., Sato, Y.S., and Kokawa, H., Texture Produced by Abnormal Grain Growth in Friction-Stir Welded Aluminum Alloy 1050, Metall. Mater. Trans. A, 2013, vol. 44, pp. 1153-1157. doi 10.1007/s11661-012-1596-4

51. Birol, Y., Evolution of Grain Structure Across Joints in Friction Stir Welded EN AW 5083 H111 Plates during Thermal Exposure, Mater. Sci. Technol., 2013, vol. 29, pp. 1283-1289. doi 10.1179/1743284713Y.0000000272

52. Liu, F.C., Ma, Z.Y., and Chen, L.Q., Low-Temperature Superplasticity of Al-Mg-Sc Alloy Produced by Friction-Stir Processing, Scripta Mater., 2009, vol. 60, pp. 968-971. doi 10.1016/j.scriptamat.2009.02.021

53. Sharma, C., Dwivedi, D.K., and Kumar, P., Effect of Post Weld Heat Treatments on Microstructure and Mechanical Properties of Friction Stir Welded Joints of Al-Zn-Mg Alloy AA7039, Mater. Design, 2013, vol. 43, pp. 134-143. doi 10. 1016/j.matdes.2012.06.018

54. Goloborodko, A., Ito, T., Yun, X., Motohashi, Y., and Itoh, G., Friction Stir Welding of a Commercial 7075-T6 Aluminum Alloy: Grain Refinement, Thermal Stability and Tensile Properties, Mater. Trans., 2004, vol. 45, pp. 25032508. doi 10.2320/matertrans.45.2503

55. Safarkhanian, M.A., Goodarzi, M., and Boutorabi, S.M.A., Effect of Abnormal Grain Growth on Tensile Strength of Al$\mathrm{Cu}-\mathrm{Mg}$ Alloy Friction Stir Welded Joints, J. Mater. Sci., 2009, vol. 44, pp. 5452-5458. doi 10.1007/s10853-009-3735-x

56. Liu, H.J. and Feng, X.L., Effect of Post-Processing Heat Treatment on Microstructure and Microhardness of WaterSubmerged Friction Stir Processed 2219-T6 Aluminum Alloy, Mater. Design, 2013, vol. 47, pp. 101-105. doi 10.1016/ j.matdes.2012.11.056

57. Kumar, N. and Mishra, R.S., Thermal Stability of Friction Stir Processed Ultrafine Grained AlMgSc Alloy, Mater. Character., 2012, vol. 74, pp. 1-10. doi 10.1016/j.matchar.2012. 09.003

58. Jana, S., Mishra, R.S., Baumann, J.A., and Grant, G.J., Effect of Friction Stir Processing on Microstructure and Tensile Properties of an Investment Cast Al-7Si-0.6Mg Alloy, Metall. Mater. Trans. A, 2010, vol. 41, pp. 2507-2521. doi 10.1007/ s11661-010-0324-1

59. Cerri, E. and Leo, P., Mechanical Properties Evolution during Post-Welding Heat Treatments of Double-Lap Friction Stir Welded Joints, Mater. Design, 2011, vol. 32, pp. 3465-3475. doi 10.1016/j.matdes.2011.01.052

60. Liu, F.C., Xiao, B.L., Wang, K., and Ma, Z.Y., Investigation of Superplasticity in Friction Stir Processed 2219 Al Alloy, Mater. Sci. Eng. A, 2010, vol. 527, pp. 4191-4196. doi 10.1016/j.msea.2010.03.065.

61. Huang, Y.X., Wan, L., Lv, Z.L., Lv, S.X., Zhou, L., and Feng, J.C., Microstructure and Microhardness of Aluminum Alloy Friction Stir Welds with Heat Treatment, Sci. Technol.
Weld. Join., 2016, vol. 21, pp. 638-644. doi 10.1080/ 13621718.2016 .1152748

62. Malopheyev, S., Mironov, S., Vysotskiy, I., and Kaibyshev, R., Superplasticity of Friction-Stir Welded Al-Mg-Sc Sheets with Ultrafine-Grained Microstructure, Mater. Sci. Eng. A, 2016, vol. 649, pp. 85-92. doi 10.1016/j.msea.2015.09.106

63. Hu, Z.L., Wang, X.S., Pang, Q., Huang, F., Qin, X.P., and Hua, L., The Effect of Postprocessing on Tensile Property and Microstructure Evolution of Friction Stir Welding Aluminum Alloy Joint, Mater. Character., 2015, vol. 99, pp. 180187. doi 10.1016/j.matchar.2014.11.015

64. Yuan, S.J., Hu, Z.L., and Wang, X.S., Formability and Microstructural Stability of Friction Stir Welded Al Alloy Tube during Subsequent Spinning and Post Weld Heat Treatment, Mater. Sci. Eng. A, 2012, vol. 558, pp. 586-591. doi 10. 1016/j.msea.2012.08.056

65. Carcia-Bernal, M.A., Mishra, R.S., Verma, R., and Hernandez-Silva, D., Inhibition of Abnormal Grain Growth during Hot Deformation Behavior of Friction Stir Processed $5083 \mathrm{Al}$ Alloys, Mater. Sci. Eng. A, 2015, vol. 636, pp. 326-330. doi 10.1016/j.msea.2015.03.094

66. Nelaturu, P., Jana, S., Mishra, R.S., Grant, G., and Carlson, B.E., Influence of Friction Stir Processing on the Room Temperature Fatigue Cracking Mechanisms of A356 Aluminum Alloy, Mater. Sci. Eng. A, 2018, vol. 716, pp. 165-178. doi 10.1016/j.msea.2018.01.044

67. Vysotskiy, I., Malopheyev, S., Mironov, S., and Kaibyshev, R., Pre-Strain Rolling as an Effective Tool for Suppression of Abnormal Grain Growth in Friction-Stir Welded 6061 Aluminum Alloy, Mater. Sci. Eng. A, 2018, vol. 733, pp. 3942. doi 10.1016/j.msea.2018.07.026

68. Yadav, D., Bauri, R., and Chawake, N., Fabrication of Al-Zn Solid Solution via Friction Stir Processing, Mater. Character., 2018, vol. 136, pp. 221-228. doi 10.1016/j.matchar. 2017.12.022

69. Mironov, S., Malopheyev, S., Vysotskiy, I., Zhemchuzhnikova, D., and Kaibyshev, R., Effect of Pre-Strain Rolling on Annealing Behavior of Friction-Stir Welded AA6061-T6 Aluminum Alloy, Defect. Diffus. Forum, 2018, vol. 385, pp. 355-358. doi 10.4028/www.scientific.net/DDF.385.355

70. Khodabakhshi, F., Simchi, A., Kokabi, A.H., Gerlich, A.P., and Nosko, M., Effects of Post-Annealing on the Microstructure and Mechanical Properties of Friction Stir Processed Al$\mathrm{Mg}-\mathrm{TiO}_{2}$ Nanocomposites, Mater. Design, 2014, vol. 63, pp. 30-41. doi 10.1016/j.matdes.2014.05.065

71. Yadav, D., Bauri, R., Kauffmann, A., and Freudenberger, J., Al-Ti Particular Composite: Processing and Studies on Particle Twinning, Microstructure, and Thermal Stability, Metall. Mater. Trans. A, 2016, vol. 47, pp. 4226-4238. doi 10.1007/ s11661-016-3597-1

72. Guo, J., Lee, B.Y., Du, Z., Bi, G., Tan, M.J., and Wei, J., Effect of Nano-Particle Addition on Grain Structure Evolution of Friction Stir-Processed Al 6061 during Postweld Annealing, JOM, 2016, vol. 68, pp. 2268-2273. doi 10.1007/s11837016-1991-1

73. Morisada, Y., Fujii, H., Nagaoka, T., and Fukusumi, M., Effect of Friction Stir Processing with Sic Particles on Microstructure and Hardness of AZ31, Mater. Sci. Eng. A, 2006, vol. 433, pp. 50-54. doi 10.1016/j.msea.2006.06.089

74. Mironov, S., Motohashi, Y., and Kaibyshev, R., Grain Growth Behaviors in a Friction-Stir Welded ZK60 Magnesium Alloy, Mater. Trans., 2007, vol. 48, pp. 1387-1395. doi 10.2320/matertrans.MRA2007040 
75. Sun, Y. and Fujii, H., Effect of Abnormal Grain Growth on Microstructure and Mechanical Properties of Friction Stir Welded SPCC Steel Plates, Mater. Sci. Eng. A, 2017, vol. 694, pp. 81-92. doi 10.1016/j.msea.2017.04.008

76. Li, Y.J., Fu, R.D., Du, D.X., Jing, L.J., Sang, D.L., and Wang, Y.P., Effect of Post-Weld Heat Treatment on Microstructures and Properties of Friction Stir Welded Joint of 32Mn-7Cr-1Mo-0.3N Steel, Sci. Technol. Weld. Join., 2015, vol. 20, pp. 229-235. doi 10.1179/1362171815Y.0000000001

77. Humphreys, F.J. and Hatherly, M., Recrystallization and Related Phenomena, Oxford: Elsevier, 2004.

78. Humphreys, F.J., A Unified Theory of Recovery, Recrystallization and Grain Growth, Based on the Stability and Growth of Cellular Microstructures. I. The Basic Model, Acta Mater., 1997, vol. 45, pp. 4231-4240. doi 10.1016/S1359-6454(97) 00070-0

79. Humphreys, F.J., A Unified Theory of Recovery, Recrystallization and Grain Growth, Based on the Stability and Growth of Cellular Microstructures. II. The Effect of Second-Phase Particles, Acta Mater., 1997, vol. 45, pp. 5031-5039. doi 10.1016/S1359-6454(97)00173-0

80. Honeycomb, R.W.K., The Plastic Deformation of Metals, New York: St. Martin's Press, 1968.

81. Ericsson, M. and Sandstrom, R., Influence of Welding Speed on the Fatigue of Friction Stir Welds, and Comparison with MIG and TIG, Int. J. Fatigue, 2003, vol. 25, pp. 1379-1387. doi 10.1016/S0142-1123(03)00059-8.

82. Moreira, P.M.G.P., de Figueiredo, M.A.V., and de Castro, P.M.S.T., Fatigue Behavior of FSW and MIG Weldments for Two Aluminum Alloys, Theor. Appl. Fract. Mech., 2007, vol. 48, pp. 169-177. doi 10.1016/j.tafmec.2007.06.001

83. Texier, D., Atmani, F., Bocher, P., Nadeau, F., Chen, J., Zedan, Y., Vanderesse, N., and Demers, V., Fatigue Performance of FSW and GMAW Aluminum Alloys Welded Joints: Competition between Microstructural and Structural-ContactFretting Crack Initiation, Int. J. Fatigue, 2018, vol. 116, pp. 220-233. doi 10.1016/j.ijfatigue.2018.06.020

84. Uematsu, Y., Tokaji, K., Shibata, H., Tozaki, Y., and Ohmune, T., Fatigue Behavior of Friction Stir Welds without Neither Welding Flash Nor Flaw in Several Aluminum Alloys, Int. J. Fatigue, 2009, vol. 31, pp. 1443-1453. doi 10. 1016/j.ijfatigue.2009.06.015

85. Di, S.S., Yang, X.Q., Luan, G.H., and Jian, B., Comparative Study on Fatigue Properties between AA2024-T4 Friction Stir Welds and Base Materials, Mater. Sci. Eng. A, 2006, vol. 435, pp. 389-395. doi 10.1016/j.msea.2006.07.009

86. Lomolino, S., Tovo, R., and Dos Santos, J., On Fatigue Behavior and Design Curves of Friction Stir Butt-Welded Al Alloys, Int. J. Fatigue, 2005, vol. 27, pp. 305-316. doi 10.1016/ j.ijfatigue.2004.06.013

87. Dickerson, T.L. and Przydatek, J., Fatigue of Friction Stir Welds in Aluminum Alloys that Contain Root Flaws, Int. J. Fatigue, 2003, vol. 25, pp. 1399-1409. doi 10.1016/S01421123(03)00060-4

88. Oosterkamp, A., Oosterkamp, L.D., and Nordeide, A., "Kissing Bond" Phenomena in Solid-State Welds of Aluminum Alloys, Weld. J., 2004, vol. 83, p. 225-S.

89. Zhou, C., Yang, X., and Luan, G., Effect of Root Flaws on the Fatigue Property of Friction Stir Welds in 2024-T3 Aluminum Alloys, Mater. Sci. Eng. A, 2006, vol. 418, pp. 155160. doi 10.1016/j.msea.2005.11.042

90. Bussu, G. and Irving, P.E., The Role of Residual Stress and Heat Affected Zone Properties on Fatigue Crack Propagation in Friction Stir Welded 2024-T351 Aluminum Joints, Int. J.
Fatigue, 2002, vol. 25, pp. 77-88. doi 10.1016/S01421123(02)00038-5

91. John, R., Jata, K.V., and Sadananda, K., Residual Stress Effects on Near-Threshold Fatigue Crack Growth in Friction Stir Welds in Aerospace Alloys, Int. J. Fatigue, 2003, vol. 25, pp. 939-948. doi 10.1016/j.ijfatigue.2003.08.002

92. Hatamleh, O., Lyons, J., and Forman, R., Laser and Shot Peening Effects on Fatigue Crack Growth in Friction Stir Welded 7075-T7351 Aluminum Alloy Joints, Int. J. Fatigue, 2007, vol. 29, pp. 421-434. doi 10.1016/j.ijfatigue.2006.05.007

93. Hatamleh, O., A Comprehensive Investigation on the Effect of Laser and Shot Peening on Fatigue Crack Growth in Friction Stir Welded AA 2195 Joints, Int. J. Fatigue, 2009, vol. 31, pp. 974-988. doi 10.1016/j.ijfatigue.2008.03.029

94. Fratini, L., Pasta, S., and Reynolds, A.P., Fatigue Crack Growth in 2024-T351 Friction Stir Welded Joints: Longitudinal Residual Stress and Microstructural Effects, Int. J. Fatigue, 2009, vol. 31, pp. 495-500. doi 10.1016/j.ijfatigue. 2008.05.004

95. Hassanifard, S., Mousavi, H., and Varvani-Farahani, A., The Influence of Low-Plasticity Burnishing Process on the Fatigue Life of Friction-Stir-Processed Al 7075-T6 Samples, Fatigue Fract. Eng. Mater. Struct., 2019, vol. 42, pp. 764772. doi $10.1111 /$ ffe. 12950

96. Li, W.Y., Li, N., Yang, X.W., Feng, Y., and Vairis, A., Impact of Cold Spraying on Microstructure and Mechanical Properties of Optimized Friction Stir Welded AA2024-T3 Joint, Mater. Sci. Eng. A, 2017, vol. 702, pp. 73-80. doi 10.1016/ j.msea.2017.07.003

97. Jata, K.V., Sankaran, K.K., and Ruschau, J.J., Friction-Stir Welding on Microstructure and Fatigue of Aluminum Alloy 7050-T7451, Metall. Mater. Trans. A, 2000, vol. 31, pp. 21812192. doi 10.1007/s11661-000-0136-9

98. Rodrigues, D.M., Loureiro, A., Leitao, C., Leal, R.M., Chaparro, B.M., and Vilaca, P., Influence of Friction Stir Welding Parameters on the Microstructural and Mechanical Properties of AA6016-T4 Thin Welds, Mater. Design, 2009, vol. 30 pp. 1913-1921. doi 10.1016/j.matdes.2008.09.016

99. Cavaliere, P., Cabibbo, M., Panella, F., and Squillace, A., 2098 Al-Li Plates Joined by Friction Stir Welding: Mechanical and Microstructural Behavior, Mater. Design, 2009, vol. 30, pp. 3622-3631. doi 10.1016/j.matdes.2009.02.021

100. Cavaliere, P., Cerri, E., and Squillace, A., Mechanical Response of 2024-7075 Aluminum Alloys Joined by Friction Stir Welding, J. Mater. Sci., 2005, vol. 40, pp. 3669-3676. doi 10.1007/s10853-005-0474-5

101. Sun, G., Wang, C., Wei, X., Shang, D., and Chen, S., Study on Small Fatigue Crack Initiation and Growth for Friction Stir Welded Joints, Mater. Sci. Eng. A, 2019, vol. 739, pp. 71-85. doi 10.1016/j.msea.2018.10.002

102. Maggiolini, E., Benasciutti, D., Susmel, L., Hattingh, D.G., James, M.N., and Tovo, R., Friction Stir Welds in Aluminum: Design S-N Curves from Statistical Analysis of Literature Data, Fatigue Fract. Eng. Mater. Struct., 2018, vol. 41, pp. 2212-2230. doi 10.1111/ffe.12805

103. Kim, S., Lee, C.G., and Kim, S.-J., Fatigue Crack Propagation Behavior of Friction Stir Welded 5083-H32 and 6061T651 Aluminum Alloys, Mater. Sci. Eng. A, 2008, vol. 478, pp. 56-64. doi 10.1016/j.msea.2007.06.008

104. Cavalire, P., Campanile, G., Panella, F., and Squillace, A., Effect of Welding Parameters on Mechanical and Microstructural Properties of AA6056 Joints Produced by Friction Stir Welding, J. Mater. Process. Technol., 2006, vol. 180, pp. 263-270. doi 10.1016/j.jmatprotec.2006.06.015 
105. He, C., Liu, Y., Dong, J., Wang, Q., Wagner, D., and Bathias, C., Through Thickness Property Variations in Friction Stir Welded AA6061 Joint Fatigued in Very High Cyclic Fatigue Regime, Int. J. Fatigue, 2016, vol. 82, pp. 379-386. doi 10.1016/j.ijfatigue.2015.08.013

106. Deng, C., Gao, R., Gong, B., Yin, T., and Liu, Y., Correlation between Micro-Mechanical Property and Very High Cycle Fatigue (VHCF) Crack Initiation in Friction Stir Welds of 7050 Aluminum Alloy, Int. J. Fatigue, 2017, vol. 104, pp. 283-292. doi 10.1016/j.ijfatigue.2017.07.028

107. Effertz, P.S., Infante, V., Quintino, L., Suhuddin, U., Hanke, S., and dos Santos, J.F., Fatigue Life Assessment of Friction Spot Welded 7050-T76 Aluminum Alloy Using Weibull Distribution, Int. J. Fatigue, 2016, vol. 87, pp. 381390. doi 10.1016/j.ijfatigue.2016.02.030

108. Sato, Y.S., Takauchi, H., Park, S.H.C., and Kokawa, H., Characteristics of the Kissing Bond in Friction Stir Welded Al Alloy 1050, Mater. Sci. Eng. A, 2005, vol. 405, pp. 333338. doi 10.1016/j.msea.2005.06.008

109. Sato, Y.S., Kokawa, H., Enomoto, M., Jogan, S., and Hashimoto, T., Precipitation Sequence in Friction Stir Weld of 6063 Aluminum during Aging, Metall. Mater. Trans. A, 1999, vol. 30, pp. 3125-3130. doi 10.1007/s11661-9990223-5

110. Woo, W., Choo, H., Withers, P.J., and Feng, Z., Prediction of Hardness Minimum Locations during Natural Aging in an Aluminum Alloy 6061-T6 Friction Stir Weld, J. Mater. Sci., 2009, vol. 44, pp. 6302-6309. doi 10.1007/s10853-0093868-y

111. Gallais, C., Simar, A., Fabregue, D., Denquin, A., Lapasset, G., de Meester, B., Brechet, Y., and Pardoen, Y., Multiscale Analysis of the Strength and Ductility of AA 6056 Aluminum Friction Stir Welds, Metall. Mater. Trans. A, 2007, vol. 38, pp. 964-981. doi 10.1007/s11661-007-9121-x

112. Sato, Y.S. and Kokawa, H., Distribution of Tensile Property and Microstructure in Friction Stir Weld of 6063 Aluminum, Metall. Mater. Trans. A, 2001, vol. 32, pp. 3023-3031. doi 10.1007/s11661-001-0177-8

113. Humphreys, F.J., Quantitative Metallography by Electron Backscattered Diffraction, J. Micros., 1999, vol. 195, pp. 170-185. doi 10.1046/j.1365-2818.1999

114. Fitzpatrick, M.E., Fry, A.T., Holdway, P., Kandil, F.A., Shackleton, J., and Suominen, L., NPL Measurement Good Practice Guide No. 52, 2005.

115. Vysotskiy, I., Malopheyev, S., Rahimi, S., Mironov, S., and Kaibyshev, R., Unusual Fatigue Behavior of Friction-Stir Welded Al-Mg-Si Alloy, Mater. Sci. Eng. A, 2019, vol. 760, pp. 277-286. doi 10.1016/j.msea.2019.06.005

116. Esmaeili, S., Wang, X., Lloyd, D.J., and Poole, W.J., On the Precipitation-Hardening Behavior of the Al-Mg-Si-Cu Alloy AA6111, Metall. Mater. Trans. A, 2003, vol. 34, pp. 751763. doi 10.1007/s11661-003-0110-4

117. Wang, X., Esmaeili, S., and Lloyd, D.J., The Sequence of Precipitation in the Al-Mg-Si-Cu Alloy AA6111, Metall. Mater. Trans. A, 2006, vol. 37, pp. 2691-2699. doi 10. 1007/BF02586103

118. Liu, G., Murr, L.E., Niou, C-S., McClure, J.C., and Vega, F.R., Microstructural Aspects of the Friction-Stir Welding of 6061-T6 Aluminum, Scripta Mater., 1997, vol. 37, pp. 355361. doi 10.1016/S1359-6462(97)00093-6

119. Woo, W., Choo, H., Brown, D.W., and Feng, Z., Influence of the Tool Pin and Shoulder on Microstructure and Natural Aging Kinetics in a Friction-Stir-Processed 6061-T6 Alumi- num Alloy, Metall. Mater. Trans. A, 2007, vol. 38, pp. 6976. doi 10.1007/s11661-006-9034-0

120. Cui, L., Yang, X., Zhou, G., Xu, X., and Shen, Z., Characteristics of Defects and Tensile Behaviors on Friction Stir Welded AA6061-T4 T-Joints, Mater. Sci. Eng. A, 2012, vol. 543, pp. 58-68. doi 10.1016/j.msea.2012.02.045

121. Liu, F.C. and Ma, Z.Y., Influence of Tool Dimension and Welding Parameters on Microstructure and Mechanical Properties of Friction-Stir-Welded 6061-T651 Aluminum Alloy, Metall. Mater. Trans. A, 2008, vol. 39, pp. 2378-2388. doi 10.1007/s11661-008-9586-2

122. Prangnell, P.B. and Heason, C.P., Grain Structure Formation during Friction Stir Welding Observed by the "Stop Action Technique”, Acta Mater., 2005, vol. 53, pp. 3179-3192. doi 10.1016/j.actamat.2005.03.044

123. Fonda, R.W., Bingert, J.F., and Colligan, K.J., Development of Grain Structure during Friction Stir Welding, Scripta Mater., 2004, vol. 51, pp. 243-248. doi 10.1016/j.scriptamat. 2004.04.017

124. Mironov, S., Inagaki, K., Sato, Y.S., and Kokawa, H., Effect of Welding Temperature on Microstructure of Friction-Stir Welded Aluminum Alloy 1050, Metall. Mater. Trans., 2015, vol. 46, pp. 783-790. doi 10.1007/s11661-014-2651-0

125. Ashby, M.F., The Deformation of Plastically Non-Homogeneous Materials, Philos. Mag., 1970, vol. 21, pp. 399424. doi 10.1080/14786437008238426

126. Fonda, R.W. and Knipling, K.E., Texture Development in Friction Stir Welds, Sci. Technol. Weld. Join., 2011, vol. 16, pp. 288-294. doi 10.1179/1362171811Y.0000000010

127. Li, S., Beyerlein, I.J., and Bourke, M.A.M., Texture Formation during Equal Channel Angular Extrusion of FCC and BCC Materials: Comparison with Simple Shear, Mater. Sci. Eng. A, 2005, vol. 394, pp. 66-77. doi 10.1016/j.msea.2004. 11.032

128. Humphreys, F.J. and Ardakani, M.G., The Deformation of Particle-Containing Aluminum Single Crystals, Acta Metall. Mater., 1994, vol. 42, pp. 749-761. doi 10.1016/09567151(94)90272-0

129. Wert, J.A., Macroscopic Crystal Rotation Patterns in Rolled Aluminum Single Crystals, Acta Mater., 2002, vol. 50, pp. 3125-3139. doi 10.1016/S1329-6454(02)00113-7

130. Kashihara, K. and Shibayanagi, T., Active Slip Systems Evaluated by a Crystal Rotation Axis Method in Cold-Rolled Cube-Oriented Aluminum Single Crystals, Mater. Trans., 2009, vol. 50, pp. 2192-2200. doi 10.2320/matertrans.LM2009820

131. ASM Handbook: Fractography, ASM Int. Materials Information Soc. USA, 1987, vol. 12.

132. ASM Handbook: Fracture and Fatigue, ASM Int. Materials Information Soc. USA, 1996, vol. 19.

133. Estrin, Y. and Vinogradov, A., Fatigue Behavior of Light Alloys with Ultrafine Grain Structure Produced by Severe Plastic Deformation: An Overview, Int. J. Fatigue, 2010, vol. 32, pp. 898-907. doi 10.1016/j.ifatigue.2009.06.022

134. Mughrabi, H. and Hoppel, H.W., Cyclic Deformation and Fatigue Properties of Very Fine-Grained Metals and Alloys, Int. J. Fatigue, 2010, vol. 32, pp. 1413-1427. doi 10.1016/ j.ifatigue.2009.10.007

135. Vinogradov, A., Washikita, A., Kitagawa, K., and Kopylov, V.I., Fatigue Life of Fine-Grain Al-Mg-Sc Alloys Produced by Equal-Channel Angular Pressing, Mater. Sci. Eng. $A$, 2003, vol. 349, pp. 318-326. doi 10.1016/S09215093(02)00813-4 